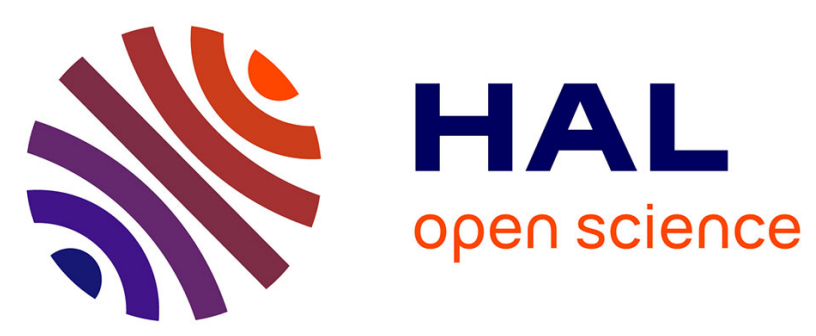

\title{
The impact of diabetes on heart failure development: the cardio-renal-metabolic connection
}

Paul Valensi, Gaétan Prévost, Sara Pinto, Jean-Michel Halimi, Erwan Donal

\section{To cite this version:}

Paul Valensi, Gaétan Prévost, Sara Pinto, Jean-Michel Halimi, Erwan Donal. The impact of diabetes on heart failure development: the cardio-renal-metabolic connection. Diabetes Research and Clinical Practice, 2021, 175, pp.108831. 10.1016/j.diabres.2021.108831 . hal-03222646

\section{HAL Id: hal-03222646 https://hal.science/hal-03222646}

Submitted on 14 Jun 2021

HAL is a multi-disciplinary open access archive for the deposit and dissemination of scientific research documents, whether they are published or not. The documents may come from teaching and research institutions in France or abroad, or from public or private research centers.
L'archive ouverte pluridisciplinaire HAL, est destinée au dépôt et à la diffusion de documents scientifiques de niveau recherche, publiés ou non, émanant des établissements d'enseignement et de recherche français ou étrangers, des laboratoires publics ou privés. 


\section{The impact of diabetes on heart failure development:}

\section{the cardio-renal-metabolic connection}

\section{Paul Valensi ${ }^{1}$, Gaétan Prévost ${ }^{2}$, Sara Pinto ${ }^{1}$, Jean-Michel Halimi ${ }^{3}$, Erwan Donal ${ }^{4}$}

${ }^{1}$ Unit of Endocrinology-Diabetology-Nutrition, AP-HP, Jean Verdier Hospital, Paris 13 University, Sorbonne Paris Cité, CRNH-IdF, CINFO, Bondy, France

${ }^{2}$ Department of Endocrinology, Diabetes and Metabolic Diseases, Normandie Univ, UNIROUEN, Rouen University Hospital, 76000 Rouen, France

${ }^{3}$ Department of Nephrology, CHU Tours, France and EA4245, Tours University, Tours, France.

${ }^{4}$ Department of Cardiology, University of Rennes, CHU Rennes, INSERM, LTSI-UMR 1099, Rennes, France

\section{Corresponding author :}

Professor Paul Valensi

Unit of Endocrinology-Diabetology-Nutrition

Hôpital Jean Verdier

Avenue du 14 Juillet. 93140. Bondy. France

Tel: +33148026580

Fax: +33148026579

e-mail: paul.valensi@aphp.fr 


\section{Abstract}

Heart failure (HF) and chronic kidney disease (CKD) are often associated in type 2 diabetes (T2D), aggravate each other and exert synergistic effects to increase the risk of cardiac and renal events. The risks of renal worsening in $\mathrm{HF}$ patients and HF in CKD patients need to be evaluated to tailor preventive therapy. The recent $\mathrm{CV}$ and renal trials enriched our knowledge about the natural history of $\mathrm{HF}$ and $\mathrm{CKD}$ in T2D and provided evidence for the benefit of sodium-glucose cotransporter 2 inhibitors (SGLT2is) in HF and renal decline prevention. SGLT-2is are the best choice in patients with HFrEF to improve CV prognosis and HF-related outcomes and also to prevent kidney-related outcomes, and in CKD patients to slow down renal failure and also reduce hHF and CV death. In both situations the number of patients to treat in order to prevent such events in one patient is lower than in the general T2D population at high CV risk. GLP1-receptor agonists could be an alternative in a patient who is intolerant or has a contraindication to SGLT-2is. A tight collaboration between diabetologists, nephrologists and cardiologists should be encouraged for a holistic and effective strategy to reduce the burden of cardio-renal-metabolic interaction.

Key-words: Diabetes, heart failure, chronic kidney disease, coronary artery disease, SGLT2 inhibitors, GLP1-receptor agonists 


\section{Introduction}

Heart failure (HF) is with coronary artery disease (CAD) the leading cause of morbidity and mortality in patients with diabetes. HF and renal failure are often associated. In a recent large multinational study of patients with type 2 diabetes (T2D) free of cardio-vascular (CV) and renal disease, HF and chronic kidney disease (CKD) were the most frequent first major manifestations and were associated with increased mortality risk, and their combination was associated with the highest CV and all-cause mortality risk [1].

The recent $\mathrm{CV}$ outcomes trials (CVOTs), both the foundation trials, i.e. the first ones which were performed in large populations of T2D patients at high CV risk, and the trials performed later which included patients with HF or CKD, provided major information about the natural history of these two complications and about the so-called cardio-renal syndrome. The cardio-renal risk should be seen as an entity and be prevented in a holistic way, requiring an early detection and appropriate management of HF and CKD. These trials provide strong evidence for the benefit of the new glucose-lowering drugs (GLDs) and particularly the inhibitors of sodium-glucose cotransporter 2 (SGLT2is) in the prevention and treatment of HF and renal failure in T2D patients and also in the patients without diabetes, raising the interest of the cardio-renal-metabolic connection.

In the present paper the situations of patients with advanced CKD with GFR $<30 \mathrm{ml} / \mathrm{min} / 1.73 \mathrm{~m}^{2}$ (G4 and G5 categories in KDIGO stratification [2]), on dialysis and kidney transplant recipients will not be covered since they represent populations with particular characteristics, a limited amount of data is available and these patients are usually excluded from HF trials and CVOTs in patients with diabetes. Our aim is to summarize the interlink between CKD and HF risks and the current standard of medical management of cardio-renal disease in the patients living with diabetes with an emphasis on the role of SGLT2is.

\section{Risks of HF and CKD in the patients with diabetes. Epidemiological data}

\subsection{Predictors of HF and more severe outcomes in the population with diabetes}

\subsubsection{Predictors of $\mathrm{HF}$}

Risk factors for HF in patients with diabetes include age, diabetes duration, insulin treatment, body mass index, CAD, albuminuria or kidney failure [3,4]. Inadequate blood pressure [5] and glucose [6] control are also associated with the risk of HF. In a cohort study from the Swedish National Diabetes Register including over 270,000 patients with T2D matched with over 1.3 million controls free of diabetes, HbA1c and low estimated glomerular filtration rate (eGFR) level were among the strongest predictors of incident hospitalization for HF (hHF) [7]. 


\subsubsection{Outcomes of HF}

The prognosis of patients with HF with reduced ejection fraction (HFrEF) is more severely impaired in those with diabetes than in their counterpart without diabetes as shown for in PARADIGM-HF (Prospective Comparison of ARNI With ACEI to Determine Impact on Global Mortality and Morbidity in Heart Failure) [8]. More recently, EMPAREG-reduced and DAPA-HF, two CVOTs which tested SGLT2is in HFrEF patients, showed that the patients with diabetes were also exposed to a higher risk of hHF and CV death compared to those without diabetes [9]. In patients with $\mathrm{HFpEF}$, the prognosis is somehow as severe as in patients with HF with reduced ejection fraction but the impact of co-morbidities like CKD and diabetes is even greater [10].

\subsubsection{Incident diabetes in HF patients and prognostic implication}

In the Cardiovascular Health Study, a prospective cohort study of CV risk in adults aged $\geq 65$ years, HF at baseline was associated with increased odds of developing impaired fasting glucose or overt diabetes after 3 or 4 years [11]. In DAPA-HF study, an exploratory analysis was performed in the subgroup with no prior history of diabetes and with $\mathrm{HbAlc}<6.5 \%$ at baseline [12]. Over a median follow-up of 18 months, more than $95 \%$ of the patients who developed diabetes (as defined by HbA1c $>6.5 \%$ ) had prediabetes at baseline (HbA1c 5.7-6.4\%) and those with incident diabetes had higher BMI and lower eGFR.

Glucose intolerance and HF share some pathophysiological factors. In particular arterial underfilling stimulates cardiovascular baroreceptors that activate sympathetic nervous system leading to an insulin resistant state while other factors associated with HF such as physical inactivity or certain drugs (diuretics) may also promote insulin resistance.

\subsection{Heart and renal failure: co-existence and mutual risk aggravation}

HF and renal failure are often associated in the same patients, especially in the population with diabetes, aggravate each other and exert synergistic effects towards an increased risk of major cardiac and renal events.

\subsubsection{CKD exposes to more HF with a more severe prognosis}

Patients with CKD exhibit an increased risk of developing HF. In the Heart Outcomes Prevention Evaluation (HOPE) study a clear relationship between the magnitude of albuminuria and the risk of hHF was found in individuals with or without diabetes [13]. In the community-based Framingham Heart Study, microalbuminuria was associated with a higher incidence of HFrEF [14]. Data from the ADHERE database showed that more than $60 \%$ of patients hospitalized with acute decompensated 
HF presented with renal dysfunction and that in-hospital mortality gradually increased from moderate to severe renal failure [15]. An analysis of the CHARM program showed that among patients with HFrEF or HFpEF impaired renal function was independently associated with the risk of hHF and CV death [16].

More recently, CVOTs showed the same trend. Among the patients included in DAPA-HF trial [17] and EMPEROR-reduced [18], all of them with HFrEF, the proportion of patients with renal impairment at inclusion was markedly higher than in the foundation SGLT2is CVOTs (EMPA-REG OUTCOME [19], CANVAS [20], DECLARE-TIMI 58 [21] and VERTIS [22]) (Figure 1A). In addition, in DAPA-HF the risk for the composite outcome of hHF and CV death was greater in the patients with eGFR $<60 \mathrm{ml} / \mathrm{min} / 1.73 \mathrm{~m}^{2}$ vs patients with greater eGFR values [17].

Looking at the placebo arms of CVOTs, the incidence rate of hHF was markedly higher in the trials dedicated to patients with CKD (DAPA-CKD [23] and CREDENCE [24] than in the foundation SGLT2i trials or the GLP1-RAs trials [25-30] (Figure 1B). In addition, in DAPA-CKD the incidence rate of hHF or CV death was three-times higher in the patients with diabetes [31].

Altogether the data indicate that both lower eGFR and albuminuria are powerful indicators not only of the risk of renal events but also of HF.

\subsubsection{HF exposes to more renal failure}

In a population of US Veterans with normal kidney function the individuals with HF at baseline had increased risks of incident CKD, and incident CKD or mortality [32]. Among 1,004 patients admitted for a primary diagnosis of $\mathrm{HF}$, worsening renal function developed in $27 \%$ and history of prior $\mathrm{HF}$ and diabetes was among the major predictors for this renal outcome [33]. Among 865 patients with diabetes followed-up in a nephrology setting, 20\% of them had a history of HF at the time of nephrology referral; a history of atrial fibrillation and HF was associated with an increased risk of reduced baseline eGFR; in turn, reduced baseline eGFR resulted in a greater risk of new major CV events, especially HF, at follow-up, and these new CV events were independent risk factors for subsequent end-stage kidney disease [34]. Along the same line, in the DAPA-CKD trial, 13\% and $8 \%$ of patients with and without diabetes, respectively, had a history of HF [31].

Among the patients included in DAPA-HF and EMPEROR-reduced trials, the incidence rate of the renal outcomes in the placebo arm was higher than in the foundation SGLT2i CVOTs (Figure 1B). In addition, in EMPEROR-reduced the renal prognosis was more severe in patients with than without diabetes, with two-fold higher rates of decline in eGFR and renal outcomes (chronic dialysis, renal transplant or sustained reduction of $\geq 40 \%$ eGFR) [35]. 


\section{Etiologies and mechanisms of $\mathrm{HF}$ in the patients with diabetes and CKD}

In patients with renal failure and even more when renal failure is associated with diabetes, hypertension and CAD are highly prevalent, leading to myocardial fibrosis, decrease in left ventricle (LV) compliance, and diastolic and/or systolic dysfunction. LV concentric remodeling is associated with impaired myocardial energetics. Thus, among the CKD patients with and without diabetes, more than half of HF patients have preserved ejection fraction. Increase in afterload and in myocardial stiffness translate into diastolic dysfunction, left atrial enlargement, and frequent atrial arrhythmias.

\subsection{CAD is a leading cause of HF in CKD patients}

Patients with diabetes and CKD are at very high risk of myocardial infarction [36]. In fact, CAD is often silent in the population with diabetes and silent CAD may similarly impair CV prognosis [37]. In asymptomatic patients with diabetes and other risk factors the prevalence of silent myocardial ischemia (SMI) detected by stress tests is usually around $20-30 \%$ [38], although this prevalence is decreasing in relation with a better control of risk factors. SMI is associated with significant coronary stenoses on angiography in 40 to $90 \%$ of the cases whereas in the other patients, ischemia may result from endothelial dysfunction, reduced coronary reserve or abnormal coronary microcirculation [38]. SMI is associated with a worse CV prognosis [38]. Whether or not SMI may lead to HF is not clearly established [39]. However, as recently reviewed, silent myocardial infarction is associated with an increased risk of HF, independent from usual risk factors [40].

Regarding silent CAD in CKD patients, the Chronic Renal Insufficiency Cohort study showed that among patients with $\mathrm{CKD}$, diabetes and higher $\mathrm{HbA1c}$ level were among the main predictors of increased coronary artery calcium (CAC) score [41]. Among the patients with diabetes the prevalence of SMI as detected by cardiac stress imaging is very high in those with proteinuria or low eGFR [38].

\subsection{Diabetic cardiomyopathy and CKD}

Diabetic cardiomyopathy (DCM) is defined as a direct diabetes-related myocardial lesion occurring independently of CAD or hypertension. Evidence for DCM is based on epidemiological findings of HF occurring in patients free of CAD, hypertension or other causes, and on echocardiographic observations [42]. Recently, in DISCOVER study [43], a 3-year, prospective, observational study of T2D patients enrolled at initiation of second-line glucose-lowering therapy, $2.1 \%$ had a diagnosis of HF at enrolment, patients with HF were more likely to be older, and have a longer duration of T2D, more CAD (44\% vs. $6 \%$ ), more atrial arrhythmias (21\% vs. $1 \%$ in non-HF patients) and CKD (23\% vs. 4\%). At follow-up the majority of incident cases of HF occurred in the absence of known CAD. 
The metabolic changes seen in diabetes (hyperinsulinemia, hyperglycemia and oxidative stress) result in increased fatty acid metabolism and fetal gene expression, and promote myocardial inflammation, fibrosis, and cardiac remodeling. Functional changes in the coronary microcirculation [44] and cardiac autonomic dysfunction are also involved. Whereas LV ejection fraction is often preserved in diabetes, the altered metabolic milieu can contribute to chamber remodeling, LV hypertrophy and diastolic dysfunction, and subtle impairment of myocardial systolic function. Myocardial hypertrophy occurs as a compensatory mechanism to pressure overload in hypertension. Hypertrophy is associated with interstitial fibrosis, changes in cardiomyocyte metabolism, myocyte apoptosis, and microvascular dysfunction. These myocardial changes exist in diabetes but even more when diabetes is associated with other risk factors like obesity [45], hypertension and CKD [46]. They lead to impaired myocardial relaxation and cardiomyocyte resting tension, and ultimately to diastolic and systolic dysfunction. An echocardiographic study reported the presence of LV hypertrophy in onethird of asymptomatic patients with T2D and of LV dilatation, systolic dysfunction or hypokinesia in $<10 \%$. Microalbuminuria was an independent predictor of these abnormalities [47].

While DCM remains an imperfectly described entity, CKD and diabetes both promote HFpEF, LV hypertrophy and diastolic dysfunction that is observed in DCM.

\subsection{Pathophysiology of the links between $\mathrm{HF}$ and CKD in patients with diabetes}

\subsubsection{Some common factors}

Additionally to hypertension, biochemical cascade downstream to hyperglycaemia, inflammatory processes, oxidative stress, RAAS activation, and an increase in sympathetic activity are also likely to contribute to both disorders. The enhanced activity of afferent sensory nerves from the kidney to the central nervous system which results from chronic hypoxia of the renal tubules and interstitium, and downstream systemic sympathetic hyperactivity are found in hypertension and T2D and also in HF and chronic renal failure [48-50].

\subsubsection{From CKD to HF and vice-versa}

CKD may contribute to impair LV structure and function through various mechanisms, including an increase in pre-load (hypervolemia) and after-load (hypertension, impaired 24h blood pressure variability, artery stiffness).

In patients with HF, the pathophysiology of renal function decline is not completely understood. The traditional view that low cardiac output results in decreased renal perfusion pressure is probably true but it was shown that congestion (preload) plays a major role in kidney function decline. Elevated 
central venous pressure and intra-abdominal pressure are associated with reduced GFR [51-53]. In a rat model, inferior vena cava ligature between the renal veins to induce congestion in the left kidney was shown to result in reduced renal blood flow and GFR associated with increased renal interstitial hydrostatic pressure. Tubulointerstitial and glomerular injury and medullary thick ascending limb hypoxia were observed. Molecules related to extracellular matrix expansion, tubular injury, and focal adhesion were upregulated and pericyte detachment was found, indicating that compression of the peritubular capillaries and tubules, hypoxia and physical stress induce pericyte detachment, and as a consequence extracellular matrix expansion and tubular injury [54].

\subsubsection{Cardiorenal syndrome (CRS)}

Numerous inter-related mechanisms are involved in the reciprocal worsening of cardiac and renal functions, including hemodynamic, neurohumoral, and inflammatory processes that potentially lead to reductions in GFR and tubular injury. CRS was initially defined as worsening kidney function that occurred during treatment for acute decompensated HF with persistent congestion and diuretic resistance. More recently, CRS has been envisioned as a spectrum of acute or chronic disorders of heart and kidney function characterized by mutual deterioration. CRS has been sub-classified into 5 types based on chronicity and the primary organ dysfunction driving the syndrome [55,56]. Acute CRS is defined as an abrupt worsening of cardiac (type 1 CRS) or kidney (type 3 CRS) function that leads to acute kidney injury or acute HF, respectively. Right-sided HF often drives type 1 CRS by producing venous congestion, which reduces renal perfusion pressure and triggers intrarenal changes that alter renal function. In type $2 \mathrm{CRS}$, pro-inflammatory state of chronic HF can cause renal tubular injury, leading to fibrosis and CKD (Figure 2). In type 4 CRS, CKD can likewise cause or intensify HF via volume and pressure overload and can aggravate cardiomyopathy due to uremic toxins and acidemia (Figure 2). Type 5 CRS involves simultaneous acute or chronic cardiac and renal dysfunction secondary to a systemic disorder (e.g. sepsis).

\section{Clinical assessment}

CRS and acute kidney injury (AKI) are increasingly prevalent among hospitalized patients with CVD and remain associated with poor short- and long-term outcomes. The Kidney Disease Improving Global Outcomes (KDIGO) guidelines define CKD as persistent reduction in glomerular filtration rate (GFR) and/or the presence of other signs of kidney damage. CKD is classified based on GFR and albuminuria categories. The lower the GFR or the higher the albuminuria level, the greater the risk of renal and cardiovascular adverse outcomes [57] 
Chronic CRS (types 2 and 4) often co-exists simultaneously with acute CRS (types 1 and 3), making difficult to distinguish CRS type in patients presenting with combined heart and kidney failure [58]. The classification of a patient in a specific CRS type may be challenging and may benefit from a careful multi-disciplinary evaluation involving cardiologists and nephrologists. An optimal management including optimized medical therapy, education, tele-monitoring is required to prevent decompensation and events that could precipitate the patient to the vicious circle that will alter both renal and cardiac prognosis.

In CKD patients with diabetes, cardiological evaluation with an ECG completed by a well-conducted rest echocardiography could help defining the subset of patients who should be more extensively tested.

Firstly, it is important to take time to question and examine patients. Indeed, HF is underdiagnosed among patients with diabetes. In a study which included 581 T2D patients older than 60 years (mean age 72 years, 65\% with hypertension, 19\% with CAD), free of history of HF and who did not complain of symptoms, HF was systematically assessed by asking questions and looking for clinical signs, and confirmed by the presence of systolic or diastolic dysfunction on echocardiography. HF was diagnosed in $28 \%$ of them, mostly as HFpEF, and CAD was considered as the most likely cause after hypertension [59].

Echocardiography assesses the structure, the size of the cavities and systolic and diastolic function. Strain imaging is encouraged and advocated by several authors. If it is decreased it can help in identifying LV segmental dysfunction related to CAD but can simply characterize the degree of LV dysfunction [60]. Indeed, some echocardiographic abnormalities including left ventricle hypertrophy associated with LV dilatation, systolic dysfunction or hypokinesia were shown to be highly predictive of the presence of silent CAD [42,47]. Such findings consistent with the role of ischemic disease in LV remodeling and indicative of a potential increased risk of HF should lead to consider assessing the patient for silent CAD. This can be done by measuring CAC score by CT-scan or performing an echocardiography or SPECT-imaging stress test [38]. Similarly, the patients with HF without clear etiology should be assessed for CAD [39].

To note, patients with severe CKD as defined by macroproteinuria or eGFR $<30 \mathrm{ml} / \mathrm{min} / 1.73 \mathrm{~m}^{2}$ are considered at very high coronary risk, and recent guidelines encourage screening these patients for silent CAD [38,61]. 


\section{How to evaluate the cardio-renal risk in a patient with diabetes? (Figure 3)}

\subsection{How to evaluate the risk of HF in patients with CKD?}

\subsubsection{Predictors of HF in contemporary studies. Risk scoring}

Several risk stratification tools for HF are available [62]. A multivariable clinical risk score for hHF was derived from the population included in the placebo arm of SAVOR-TIMI 53 (Saxagliptin Assessment of Vascular Outcomes Recorded in Patients With Diabetes Mellitus-Thrombolysis in Myocardial Infarction 53) trial. Five variables were included in this risk model: history of HF, history of atrial fibrillation, CAD, eGFR and urinary albumin/creatinine ratio. Then, this score was externally validated in placebo-treated patients in the DECLARE-TIMI 58 trial (Dapagliflozin Effect on Cardiovascular Events-Thrombolysis in Myocardial Infarction 58) [63]. Interestingly, although relative risk reductions for hHF with dapagliflozin were similar for patients across the risk scores, absolute risk reductions were greater in those at higher baseline risk [63]. In the same line, the 5-year risk for incident HF using the 9-variable Health ABC HF Risk score [64], a validated HF risk score based on usual clinical and biological variables, was applied to the patients of EMPAREG OUTCOME trial without HF at baseline [65]. The incident hHF or CV death risk in the placebo arm increased with increasing HF risk profile from low or average to very high risk. The reduction of this composite outcome with empagliflozin was consistent across the groups, however again with a greater absolute risk reduction in high and very high risk groups. These data suggest that such scores might be used in clinical practice to estimate the risk of hHF and profile the patients more likely to benefit from SGLT2is while increasing the cost-effectiveness of SGLT2i treatment.

Microvascular disease is also involved in the development of HF in T2D. In the GoDARTS (Genetics of Diabetes Audit and Research Tayside Scotland) study patients with microvascular disease (retinopathy, nephropathy or neuropathy) at baseline were, after a median follow-up of 9.3 years, at higher risk of incident HF independent of a history of prior HF or MI, and CKD was one of the major predictors [66]. Similarly, the influence of microangiopathic disease on HF outcomes was examined in the setting of macrovascular disease in the EMPAREG-Outcome study [67]. In the placebo group, the presence of any microvascular disease at baseline was associated with higher risk for subsequent hHF and CV death or hHF, and with a relation between the number of microvascular complications and incident hHF. Thus, screening for HF should be prioritized in patients with microvascular disease including CKD, which might help tailoring preventive therapy to lower HF outcomes. 


\subsubsection{Evaluation of the risk of congestion}

In the patients with advanced CKD, early diagnosis of HF and treatment of congestion are essential to reduce symptoms, preserve heart and kidney function, and improve outcomes. This is even more important in the patients with renal failure and previous history of hHF. Chronic fluid overload should be prevented and managed. Echocardiography may help evaluating the risk of congestion by estimating LV filling pressure by transmitral E/e ratio. Other methods may be used including transthoracic impedance cardiography, whole-body bioelectrical impedance that assesses extra- and intra-cellular total body water, and CV biomarkers may be helpful to differentiate cardiac from noncardiac components of overhydration [68]. The diastolic stress echocardiography can also help unmasking the abnormal heart reserve to exercise [69]. Strategies for water and sodium management are available in the context of the interplay between the cardiac and renal systems [70].

\subsubsection{Role of biomarkers}

N-terminal pro-B-type natriuretic peptide (NT-proBNP) could be part of an individualized CV risk assessment of patients with diabetes. The negative predictive value of a normal value $(<125 \mathrm{pg} / \mathrm{mL})$ of NT-proBNP for short-term CV events in patients with diabetes was 98\% [71]. However, the levels of BNP and NT-proBNP are influenced by renal function. Decreased renal function is associated with a 2-fold increase of BNP and NT-proBNP in the absence of severe left ventricular dysfunction and even more in patients with severe left ventricular dysfunction [72]. The association between baseline NT-proBNP and the risk of HF is continuous. In the CRIC study in patients with CKD, as compared to patients with NT-proBNP $<33.2 \mathrm{pg} / \mathrm{ml}$ (first quintile), the relative risk of incident HF rose from 1.99 [1.15-3.43] for the second quintile $(33.2-82.2 \mathrm{pg} / \mathrm{ml})$ to 7.61 [4.49-12.90] for the 5th quintile [73]. Among various biomarkers including galectin-3, hsTroponin, growth differentiation factor-15 and soluble ST2, NT-proBNP was the best biomarker for incident HFpEF [73]. In a French cohort of patients with T2D (SURDIAGENE), midregional-proadrenomedullin (MR-proADM), soluble tumor necrosis factor receptor 1 and NT-proBNP predicted renal function loss and rapid renal decline, and the combination of the 3 biomarkers yielded the highest discrimination [74]. In another study from the same group, it was demonstrated that MR-proADM did not contribute supplementary information on prediction of HF in a model including NT-proBNP [75].

The KDIGO initiative recognized the utility of biomarkers such as NT-proBNP in the diagnosis of HF in patients with CKD but did not formally propose the use of these biomarkers to monitor HF risk in CKD populations [76]. In addition, there is no validated threshold in these patients identifying the risk of HF. 


\subsection{How to evaluate the risk of renal failure in patients with HF?}

In patients with $\mathrm{HF}$, the risk of renal function deterioration is modulated by volume overload. Among the 3718 patients of the EVEREST (Efficacy of Vasopressin Antagonism in Heart Failure Outcome Study With Tolvaptan) trial who had HFrEF (mean initial eGFR : $59 \mathrm{ml} / \mathrm{min} / 1.73 \mathrm{~m}^{2}$ ), 10\% developed stage $4 \mathrm{CKD}$ and the risk was more than 2 times greater in those in the highest quartile of baseline NT-proBNP compared with the lowest quartile [77]. Similar findings were reported for patients without HF $[78,79]$. Thus, volume overload, as indicated both by elevated natriuretic peptides and clinical signs and symptoms, is associated with increased risk for clinically important kidney function outcomes in HFrEF.

\section{How to reduce the cardio-renal risk in patients with diabetes?}

\subsection{Therapeutic armamentarium for both the prevention and treatment of $\mathrm{HF}$ and kidney disease}

\subsubsection{Lifestyle interventions and reduction of body weight}

Lifestyle interventions represent a cornerstone in the management of T2D. In obese patients lifestyle modification using a behavioral intervention program including dietary restrictions and exercise training were shown to improve LV systolic and diastolic function in those who significantly reduced body weight and/or insulin resistance, however less effectively in patients with diabetes than in those without [80]. Decreases of LV mass, septum and posterior wall thickness, and an improvement of LV diastolic function were also reported one year after bariatric surgery in patients with severe obesity [81]. However, in LOOK-AHEAD trial which included participants with recent T2D, there was no significant difference in the risk of incident HF between the intensive lifestyle intervention compared to the diabetes support and education group over a median follow-up of 12.4 years [82]. By contrast, in the same study, intensive lifestyle intervention was associated with significant risk reduction for CKD progression [83]. Other data suggest that intentional weight loss combined with exercise could improve $\mathrm{VO}_{2}$ in $\mathrm{HFpEF}$ patients [84].

Obese patients are at risk for developing proteinuria and chronic renal failure after unilateral nephrectomy [85]. In the Swedish Obese Subjects study, bariatric surgery induced better effects than conventional obesity care on remission of albuminuria and prevention of eGFR decline [86]. According to a recent meta-analysis bariatric surgery yields significant weight loss in patients with end-stage CKD that improves patients' chances of accessing a renal transplant [87]. 


\subsubsection{Optimized control of risk factors}

- Glucose control

A meta-analysis of randomized trials of intensive glucose control did not show any benefit of intensive treatment on the reduction of either hHF or HF-related mortality [88]. On the contrary, tight glycemic control was shown to prevent the onset and progression of diabetic CKD $[89,90]$.

There is no published study having tested the benefit of glycemic control specifically in patients with HF or renal failure. In SGLT2 trials the role of glycemic control in the improvement of CV and renal outcomes is controversial and probably modest.

\section{- Blood pressure control}

In the observational analysis of the United Kingdom Prospective Diabetes Study, every $10 \mathrm{~mm} \mathrm{Hg}$ decrease in systolic blood pressure level was associated with a significant $12 \%$ estimated risk reduction of HF [5]. In a recent meta-analysis, antihypertensive treatment significantly reduced HF and end-stage renal disease in patients with T2D with an achieved on-treatment mean SBP of 138 $\mathrm{mmHg}$ without further benefit, except for stroke, with an on-treatment mean SBP of $122 \mathrm{mmHg}$ [91].

\section{- Lipid control}

A meta-analysis of statin therapies reported a 21\% MACE reduction per mmol/L of LDL-C lowering in individuals with or without diabetes [92]. A recent review suggested that in patients with CV risk factors or established atherosclerotic CVD but without HF, statins may reduce the rate of hHF [93]. In addition to LDL-cholesterol lowering using statins, other lipid disorders should be considered for CV prevention. The Action to Control Cardiovascular Risk in Diabetes (ACCORD)-Lipid study found no evidence of a beneficial effect of statin-fenofibrate combined treatment compared to statins alone, on CV outcomes and mortality in T2D after 5 years of active treatment. However, a beneficial reduction in major CV events was shown in a pre-specified sub-group of patients with dyslipidemia. In addition, in the patients with dyslipidemia, fibrate treatment was associated with a legacy benefit of improved survival and reduction of congestive HF over a post-trial follow-up (ACCORDION study) [94]. A post-hoc analysis of the ACCORD-Lipid trial showed that in patients without CKD, the addition of fenofibrate was associated with a significant $36 \%$ reduction of CV mortality and $44 \%$ lower rate of fatal or non-fatal congestive HF [95].

Regarding renal effects, the ACCORD study showed a reduced progression of albuminuria with fenofibrate. A post-hoc analysis also showed that treatment with fenofibrate was associated with lower rate of eGFR decline and lower incidence of microalbuminuria and macroalbuminuria but no 
difference in incidence of kidney failure [96]. These findings support re-evaluation of fibrates as an add-on strategy to statins in order to reduce $\mathrm{CV}$ risk, $\mathrm{HF}$ and renal risk in patients with diabetes and dyslipidemia. However fenofibrate needs a dose adjustment or is contra-indicated in patients with advanced renal failure [97].

- Residual risk after multifactorial approach

In the Steno-2 study, intensified, multifactorial intervention targeting blood glucose, blood pressure and lipids for 7.8 years in T2D patients with microalbuminuria reduced the risk of hHF by $70 \%$ during a total of 21 years of observation [98] and slowed progression in nephropathy and renal function loss reducing the risk of end-stage renal disease [99]. Such multifactorial approach represents a major component of the overall management in patients with T2D. However, in a recent cohort study from the Swedish National Diabetes Register, T2D patients controlled for the major risk factors still exhibited an increased risk of HF compared to the control population [7].

\subsubsection{RAAS blockers beneficial to HF and the kidney}

Several clinical trials demonstrated that RAAS blockers reduce the risk of CKD progression and the risk of HF through mechanisms that may be independent of BP control. RENAAL and IDNT studies [100-102] showed that angiotensin 2 receptor blockers decreased hard renal outcomes by 16 and $20 \%$ and $\mathrm{hHF}$ by $32 \%$ and $23 \%$, respectively, in patients with CKD and T2D. Patients with diabetes, hypertension and CKD should be treated with a RAAS blocker [102].

\subsection{Treatment of HFrEF in patients with CKD}

In HFrEF there is good evidence for the use of beta-blockers, ACE inhibitors/ARBs, mineralocorticoid receptor antagonists (MRAs) and angiotensin receptor-neprilysin inhibitors (ARNIs) at CKD I-III stages while at stages IV-V the evidence is moderate for beta-blockers, RAAS blockers need careful monitoring, MRAs are contraindicated, and the evidence is unclear for ARNIs [103].

\subsection{Prevention of the risk of acute kidney injury}

The KDIGO initiative identified several situations leading to AKI (sepsis, critical illness circulatory shock, burns, trauma, cardiac surgery, major noncardiac surgery, nephrotoxic drugs, radiocontrast agents) and susceptibility for special groups of patients including chronic heart disease, CKD and diabetes, dehydration and volume depletion [104]. It was recommended to stratify patients for the 
risk of AKI according to their susceptibilities and exposures, and manage them to reduce the risk of $\mathrm{AKI}$, and test patients at increased risk for AKI with measurements of serum creatinine and urine output. It was proposed to individualize frequency and duration of monitoring based on patient risk and clinical course [104]. The latest KDIGO position paper identified areas of uncertainties but did not propose novelties regarding prevention and management of AKI [105].

\subsection{Effects of the old anti-hyperglycemic drugs}

Acute administration of insulin can directly stimulate renal tubular sodium reabsorption and it has been hypothesized that insulin can worse HF [106]. However, in the ORIGIN study, insulin glargine treatment at moderate dose was not associated with any change in CV outcomes including HF [107]. Insulin looks as a good choice in patients with diabetes and congestive HF and/or renal failure.

Regarding other "old" anti-hyperglycemic classes, observational studies have shown that HF incidence was lower on metformin treatment compared to sulphonylureas. A recent review synthetizing 17 observational studies showed fewer HF readmissions in patients with CKD or CHF [108]. Metformin is no longer contra-indicated in patients with HF provided they do not have advanced CKD with eGFR $<30 \mathrm{ml} / \mathrm{min} / 1.73 \mathrm{~m}^{2}$ nor acute or unstable CHF $[109,110]$.

Sulphonylurea derivatives have also been associated with an increased risk of HF in naïve patients as compared to metformin and should be used with caution because of hypoglycemic risk and weight gain effect [111].

Glitazones may favor sodium and water retention and may induce congestive HF in particular in patients with previous MI and/or HF [112], and thus are contra-indicated in patients with clinical HF. Some evidences exist suggesting a nephroprotective role of glitazones in T2D patients. A metaanalysis suggested that treatment by rosiglitazone or pioglitazone significantly decreases urinary albumin excretion in patients with diabetes [113]. Two randomized trials showed that troglitazone (vs metformin and vs glibenclamide) was able to reduce urinary albumin/creatinine ratio in patients with diabetes and microalbuminuria [114,115]. Clinical trials with hard renal outcomes are necessary to elucidate the potential benefits of glitazones on diabetic nephropathy. In addition, by impairing osteoblast differentiation and formation and increasing bone marrow adipocytes, glitazones increase the incidence of fractures [116], a risk already augmented in CKD patients. Thus, glitazones should be avoided in HF patients and the balance of risks is not favorable in CKD population.

Regarding dipeptidyl peptidase-4 inhibitors (DPP4is), in the SAVOR trial an increase $(+27 \%)$ in the rate of hHF, mostly in the patients with HF history or elevated pro-BNP levels, was reported in the saxagliptin arm [4] while in the TECOS study there was no change in hHF outcome with sitagliptin [117]. Some trend to a reduction of albuminuria was reported in some trials but without significant 
effect on eGFR decline or the progression to end-stage renal disease [118]. For all DPP4is but linagliptin (which has biliary excretion) doses must be reduced according to eGFR.

Noticeably, there is no published controlled trial performed with the old anti-hyperglycemic drugs in patients with HF or CKD.

\subsection{Effects of GLP1-RAs}

Among the new GLDs, GLP1-RAs and SGLT2is showed clear benefits on CV events, and additionally great benefits on hHF and renal outcomes with SGLT2is. Among GLP1-RAs liraglutide, semaglutide, albiglutide and dulaglutide induce a significant reduction of major CV events. Metaanalyses of CVOTs testing GLP1-RAs have reported a significant relative risk reduction of hHF (by $9 \%$ ) as compared to placebo together with a reduction of MACE by $12 \%$ [119]. Significant risk reductions were also shown for a broad composite kidney outcome (development of new-onset macroalbuminuria, decline in eGFR, progression to end-stage kidney disease, or death attributable to kidney causes $)$ by $17 \%(0 \cdot 83,0 \cdot 78-0 \cdot 89 ; \mathrm{p}<0 \cdot 0001)$. However this result was mainly driven by a reduction in urinary albumin excretion and not by hard renal outcomes [119] as also suggested by other studies [118].

\section{Role of SGLT2i in the reduction of the cardio-renal risk}

SGLT2is were shown to significantly reduce the incidence rate of major CV events and also to be highly effective in the prevention and treatment of both HF and CKD. The baseline risk for CV and renal outcomes determines the absolute benefits obtained with these agents.

\subsection{Role in the reduction of $\mathrm{HF}$}

The risk reduction of hHF is far greater with SGLT2is than with GLP-RAs (Figure 1C). The reduction is of $32 \%$ according to a recently updated meta-analysis of the foundation CVOTs performed with SGLT2is [120]. The benefit does not differ significantly whatever the patients have or do not have an history of CVD or HF [120]. In addition, in the two CVOTs dedicated to HFrEF patients with or without diabetes (DAPA-HF and EMPEROR-reduced), the risk reductions of the composite of first $\mathrm{hHF}$ and $\mathrm{CV}$ death and its two components were quite consistent, leading to reductions by $26 \%, 31 \%$ and $14 \%$ in a recent meta-analysis, without heterogeneity related to the presence of diabetes [9]. The results of trials including patients with $\mathrm{HFpEF}$ are expected. 
Primary renal outcomes in recent SGLT2is trials were not identical and therefore the comparison is not always easy. However, SGLT2is resulted in significant relative reductions of the primary renal outcome (from $-29 \%$ to $-48 \%$ ) for empagliflozin, dapagliflozin and canagliflozin (Figure 1C) with a nonsignificant reduction in VERTIS trial with ertugliflozin. The latest meta-analysis from 5 trials indicated a $38 \%$ reduction of kidney outcomes with no significant heterogeneity [120]. In DAPA$\mathrm{CKD}$, the nephroprotective effects were observed regardless of diabetes status, age, cause of CKD, baseline albuminuria $(<1000 \mathrm{mg} / \mathrm{g}$ vs $>1000 \mathrm{mg} / \mathrm{g})$ and GFR $\left(<45 \mathrm{vs}>45 \mathrm{ml} / \mathrm{min} / 1.73 \mathrm{~m}^{2}\right)$ [31]. Of note, in all SGLT2i trials, virtually all patients were treated by RAAS blockers, and SGLT2is showed a 30 to $40 \%$ further reduction of hard renal endpoints. In trials dedicated to patients with CKD, with or without diabetes, the relative risk reduction of renal outcomes was of 39\% in DAPA-CKD and $30 \%$ in CREDENCE, larger than in the foundation trials (Figure 1C).

\subsection{Effects in the context of the cardiorenal syndrome}

Major information may be drawn from subgroups analyses of the foundation CVOTs and from trials dedicated to patients with history of HF or with CKD at baseline.

\subsubsection{Considering type 2 cardiorenal syndrome, the type leading from HF to CKD}

The above-mentioned updated meta-analysis of the foundation CVOTs reported a similar 36\% reduction of kidney-related outcomes in patients with history of HF as in those without [120]. In the same line, in the meta-analysis of the two CVOTs dedicated to HFrEF patients the relative risk reduction of kidney outcomes was of the same magnitude (-38\%) [9] (Fig 1C). However, due to the higher baseline renal risk, the absolute reduction was generally greater than in the foundation SGLT2is or GLP1-RAs CVOTs (Figure 1B). These trials did not show any excess in adverse events of interest using empagliflozin or dapagliflozin compared to those in the respective placebo arms [9].

\subsubsection{Considering type 4 cardiorenal syndrome, the type leading from CKD to HF}

Interesting data were reported in a meta-analysis of three foundation CVOTs. The reduction of hHF outcome with SGLT2is was significant only for the patients with eGFR between 60 and 90 and $<60$ $\mathrm{ml} / \mathrm{min} / 1.73 \mathrm{~m} 2$ (- 31\% and - 40\%, respectively) while it was not significant for those with eGFR > $90 \mathrm{ml} / \mathrm{min} / 1.73 \mathrm{~m} 2$ [121]. A subgroup study of VERTIS which was not included in that meta-analysis showed similarly that the reductions of hHF and the composite outcome of hHF and CV death were greater in the patients with elevated albuminuria and more severe CKD stage [122]. On the contrary, in HFrEF patients the reduction of this composite CV outcome was very close whatever the patients 
had eGFR $<$ or $>60 \mathrm{ml} / \mathrm{min} / 1.73 \mathrm{~m} 2$ (-23 and $-28 \%$, respectively) [9]. Noticeably, the incidence of this outcome in the placebo arms was higher than in the other trials.

The CREDENCE study which included albuminuric patients reported a significant relative risk reduction (-31\%) of the composite of hHF or CV death [24] which did not differ significantly in the patients with or without a CV history (-34\% and - 26\%, respectively) [123]. Similarly, in DAPACKD study, $88 \%$ of whom had eGFR $<60 \mathrm{ml} / \mathrm{min} / 1.73 \mathrm{~m} 2$, the composite criterion of hHF and CV death was reduced by $29 \%$ [23], with no significant interaction related to diabetes [31]. However, in these trials, the baseline risk of hHF was higher than in the foundation SGLT2is CVOTs (Figure 1B) and the absolute hHF risk reduction was greater compared to the foundation trials and of similar magnitude compared to the trials in hHF patients (Figure 1B), indicating a lower number of patients to be treated in order to prevent an event in one patient.

Regarding safety issues, in DAPA-CKD the incidence of volume depletion events was rather low with dapagliflozin but higher than with placebo (5.9\% vs $4.2 \%)$, without any increase in diabetic ketoacidosis.

Thus, SGLT-2is are the best choice in patients with HFrEF not only to improve CV prognosis and HF-related outcomes but also to prevent kidney-related outcomes, and in CKD patients to slow down renal failure and also to reduce hHF and CV death (Figure 3). In both situations the number of patients to be treated in order to prevent such events in one patient is lower than in the general population at high CV risk. GLP-1 RAs could be an alternative in a patient who is intolerant or has a contraindication to SGLT-2is.

\subsection{SGLT2is act through various mechanisms}

\subsubsection{Mechanisms contributing to the reduction of HF outcomes}

Volume depletion plays a major role in the reduction of hHF as suggested by the mediation analyses of EMPAREG-OUTCOME study [124]. The reduction of after-load including a slight blood pressure reduction and a decrease in artery stiffness, specific changes in the myocardium metabolism, body weight lowering and an improvement of tissue oxygenation are also potentially involved [50]. Some studies also suggest the role of a reduction of sympathetic activity which may result from the reduction in intrarenal hypoxia with a restoration of the EPO-producing cell function, and in chemoreceptor-mediated activation of renal afferent sensory and efferent sympathetic fibres [50]. A reduction of LV mass has also been reported with empagliflozin [125], which would be interesting to examine in CKD patients. 


\subsubsection{Specific effects on the kidney}

Nephroprotective effects of SGLT2is do not seem to depend on blood glucose changes. Indeed, these effects persist in patients with eGFR $<45 \mathrm{ml} / \mathrm{min} / 1.73 \mathrm{~m} 2$ [126] - while blood glucose lowering is very limited [127]- and are of the same magnitude in patients with or without diabetes [31].

It was proposed that the nephroprotective effect of SGLT2is was due to their effect on intraglomerular pressure, presumably through activation of tubuloglomerular feedback in patients with type 1 diabetes (T1D) [128]. Indirect evidence was provided that intraglomerular pressure was reduced [128]by different mechanisms in T1D and T2D: SGLT2is reduce afferent arteriole vasodilatation in T1D whereas they induce vasodilation of the efferent arteriole in T2D [129]. However, whether the renal benefit is due to decreased intraglomerular pressure is not sure. The initial increase of serum creatinine after SGLT2 $\mathrm{i}$ is presumably due to a decrease in intraglomerular pressure. In this view, this phenomenon, which does not occur in all patients, should indicate long-term renal protection. However, in EMPAREG trial, only $28 \%$ of patients decreased GFR by $>10 \%$ after empagliflozin initiation (vs $10 \%$ in the placebo arm), and the long-term renal benefit of empagliflozin was independent of this short-term GFR dip [130], undermining the "intraglomerular pressure" hypothesis. Many other mechanisms were proposed including beneficial effect on mitochondria, renal sympathetic nervous system, blood pressure reduction, diminished sodium renal interstitial through mitigation of the $\mathrm{Na} / \mathrm{H}$ exchange activity, reduction of tubular cell inflammation and fibrosis, and decrease of serum uric acid [50,131-133]

\subsection{Role of glucose effect in the population free of diabetes}

There is some evidence suggesting the improvement of glucose metabolism by renin-angiotensin system inhibition, due to various mechanisms including an improvement of insulin sensitivity. In addition, several ACE inhibitors and sartans have been shown to reduce the incidence of new diabetes, by around $20 \%$ in meta-analyses [134], while the risk of developing diabetes is higher on diuretics and beta-blockers [135]. Patients with diabetes and HFrEF enrolled in PARADIGM-HF who received sacubitril/valsartan had a greater long-term reduction in HbA1c than those receiving enalapril, possibly partly due to a reduction of sympathetic activity [136]. In DAPA-HF a further reduction of incident diabetes by $32 \%$ with dapagliflozin was observed in HFrEF patients while around $90 \%$ were on RAAS blockers [12]. Since mortality was higher among the participants who developed diabetes the potential benefit of dapagliflozin to prevent the conversion from prediabetes to diabetes, while requiring mechanistic explanation, deserves being confirmed in longer duration trials. 


\section{The management of $\mathrm{HF}$ in patients with CKD requires a multi-disciplinary approach}

A tight collaboration among the diabetologist, the nephrologist and the cardiologist is the basis for a holistic and effective strategy. KDIGO, AHA and ADA recommendations share many points about the optimal management of multi-complicated diabetes, but a daily partnership should be advocated. Patients with both comorbidities require lifestyle individualized advises, tailored pharmacotherapy and $\mathrm{HbAlc}$ target and risk factors control (Table 1).

A Mediterranean diet favouring vegetables, fruits, whole grain, fibres, legumes and unsaturated fats is recommended in all patients with diabetes. When CKD is present (stage 3-5), KDOKI guidelines for nutrition recommend a sodium intake $<2.3 \mathrm{~g} / \mathrm{d}$ aiming to lower blood pressure and proteinuria and to improve volume control [137]. A prospective study showed that among patients with $\mathrm{CKD}$, higher urinary sodium excretion is associated with increased risk of CVD making salt restriction even more important in CKD patients with very high CVD risk [138]. In the past, most of cardiology associations recommended in adults with symptomatic $\mathrm{CHF}$ a reduced sodium intake $(<2 \mathrm{~g} / \mathrm{d})$. Conversely, recent evidences failed to prove a significant effect of salt restriction in improving quality of life and prognosis of patients with congestive HF and this is no more formally recommended [139]. It is presently unknown whether CKD patients (as well as subjects from the general population) should increase or reduce or have the same daily water intake to prevent further renal dysfunction and/or HF risk. In a recent study, a U-shape relationship was observed between daily water intake and degradation of renal function in 1,245 CKD patients (eGFR 15-60 ml/min/1.73m²) from the CKDREIN cohort study [140]. Nevertheless, some trials are ongoing to assess if supplemental water can slow the loss of kidney function in CKD patients [141]. Fluid restriction in congestive HF is a matter of controversy and recommended only in case of hyponatraemia [70]. Aggressive fluid and sodium restriction was reported to have no effect on weight loss or clinical stability at 3 days in patients with acute HF [142].

The glycemic target should be defined on an individual basis and achieved gradually, considering the presence and severity of CAD, HF and CKD and the risk of hypoglycemia. The treatment choice needs to consider potential benefits and harm of GLDs regarding the hypoglycemia risk. A target range of $\mathrm{HbAlc}$ from 7 to $8 \%$ for most patients with $\mathrm{HF}$ is often suggested in the clinical guidelines [143]. It is well known that HbA1c measurement is less accurate in CKD patients mostly because of frequent concomitant anaemia [144] whereas it seems to remain reliable in HF patients [145]. HF and CKD patients are at high risk of hypoglycaemia. In frail patients with diabetes, ADA Standards of care recommend less stringent $\mathrm{HbA} 1 \mathrm{c}$ target $(<8 \%)$ if limited life expectancy and harms of treatment 
are a concern [146]. In the last years, time in range (TIR) measured by continuous glucose monitoring has been proved as a good predictor of microvascular complications [147]. TIR is accurate in CKD and HF patients [148]. In frail patients the aim should be to have $50 \%$ of TIR with $<1 \%$ with interstitial glucose under $70 \mathrm{mg} / \mathrm{dl}$ [146].

With the new GLDs the risk of hypoglycaemia is strongly reduced and more ambitious glycaemic targets can be safely achieved in such patients. First-line therapy for patients displaying both HF and/or CKD includes metformin and SGLT2i, independently of metabolic control. With the limitation of eGFR (Table 2a), metformin should be the treatment of choice in patients with HF [149]. The ESCEASD guidelines even advocate the new GLDs as first-line therapy in patients with T2D and atherosclerotic CVD and those with high or very high CV risk [61]. The choice of an SGLT2i should apply mostly to patients with HF or CKD. In addition, in 2020 FDA and EMA approved dapagliflozin for HF independently of the presence of diabetes. It is likely that SGLT2i will be approved also for CKD. When starting SGLT2i, a reduction in diuretic or insulin/sulfonylurea posology may be needed to avoid hypotension or hypoglycaemia and it is recommended to monitor creatinine. When eGFR does not allow the prescription of metformin and/or SGLT2i, second-line glucose-lowering treatment includes GLP1-RA (Table 2b) and insulin can be considered if glycemic goal is not achieved.

\section{Conclusion}

The recent CV and renal trials performed with the new GLDs enrich our knowledge about the natural history of $\mathrm{HF}$ and $\mathrm{CKD}$ in patients with $\mathrm{T} 2 \mathrm{D}$ and provide strong evidence in favor of the role of SGLT2is in the prevention of HF and renal function decline and their mutual aggravation. It is time, as stated in the ESC-EASD and the new EASD-ADA guidelines [61,150] to favor the use of the new GLDs in this context. The challenge is now to help clinicians using these drugs on an individual basis. Future trials will define the potential role of combination therapy of a SGLT2 $i$ with a GLP1-RA in the prevention and management of the cardio-renal-metabolic connection.

\section{Authors' contributions}

All authors have made substantial contributions. PV and GP wrote the first draft of the manuscript. SP wrote a chapter, elaborated tables and one figure. SP, JMH and ED completed the search for papers in the literature and wrote complementary parts of the manuscript. All authors critically revised the manuscript for important intellectual content. They all read and approved the final manuscript.

\section{Competing interests}


PV discloses the following potential conflicts of interest: lectures for Abbott, AstraZeneca, Bayer, Eli Lilly, Hikma Pharmaceuticals, Merck Sharp \& Dohme, Novo Nordisk, Novartis, Pfizer, Sanofi; research grants from Abbott, Bristol-Myers-Squibb-AstraZeneca, Novo Nordisk; participation in expert committees for AstraZeneca, Boehringer Ingelheim, Novo Nordisk, Daiichi Sankyo, Sanofi, Servier, Stendo. GP discloses the potential following conflicts of interest: lectures for Abbott, AstraZeneca, Eli-Lilly, Merck-Sharp-Dohme, Novo Nordisk, Sanofi; participation to Expert Committees for Merck-Sharp-Dohme, Novo Nordisk, Sanofi. SP discloses no conflict of interest. $\mathrm{JMH}$ discloses the following potential conflicts of interest: consulting fees from Astra Zeneca, Alexion, Servier, Vifor Fresenius, Merck-Sharp-Dohme, Novo Nordisk, Boehringer Ingelheim France, Sanofi, Bayer. ED discloses the following potential conflicts of interest: consulting fees from AstraZeneca, General Electric Healthcare, Bristol-Myers-Squibb.

\section{Funding}

For this review paper the authors did not receive any specific grant from funding agencies in the public, commercial, or not-for-profit sectors.

\section{Legends of figures}

Figure 1: Cardiovascular and renal outcome trials having tested GLP1-RAs and SGLT2is.

Panel A: Prevalence of cardiovascular and renal diseases at inclusion. Panel B: Incidence of hospitalization for heart failure (hHF) or worsening nephropathy (hard renal outcomes) if available /100 patient-year. Panel C: Relative risk reduction for hHF or worsening nephropathy on active treatment compared to placebo.

$\int:$ includes macroalbuminuria. $\neq$ includes cardiovascular death.

Figure 2: Pathophysiology of type 2 and type 4 cardiorenal syndrome (CRS).

Figure 3: Potential framework for identifying patients with diabetes and cardiorenal risk likely to benefit from the new glucose-lowering treatments.

CAD : coronary artery disease. CKD : chronic kidney disease. HF : heart failure. HFrEF : HF with reduced ejection fraction. eGFR : estimated glomerular filtration rate. 


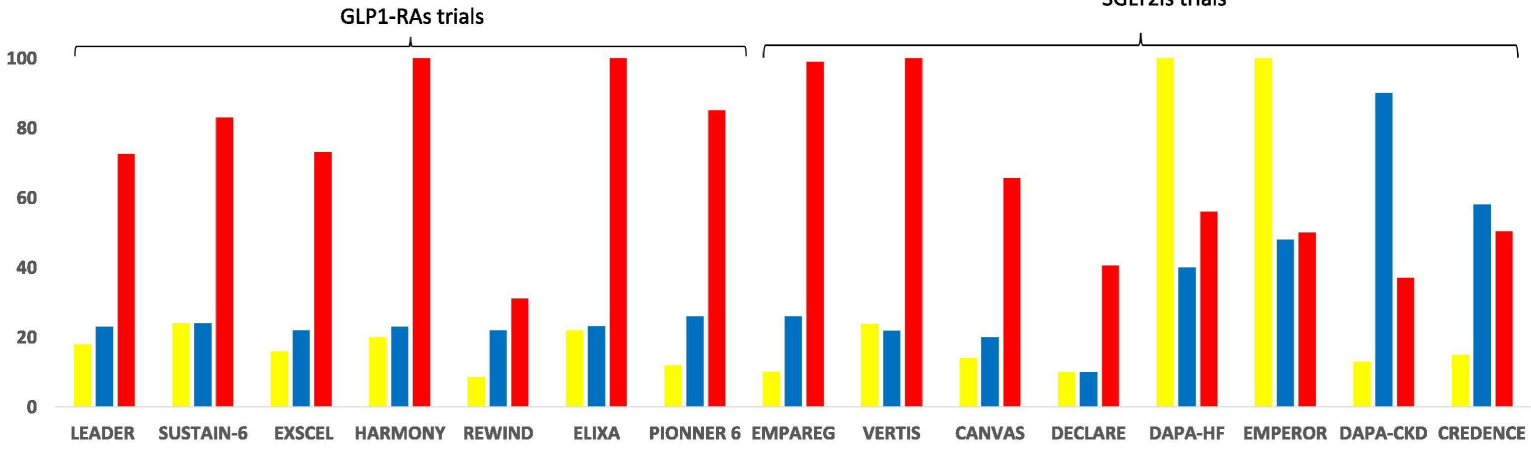

10$$
7
$$$$
6
$$$$
6
$$$$
5
$$$$
\begin{aligned}
& 4 \\
& 3 \\
& 2 \\
& 1 \\
& 0
\end{aligned}
$$
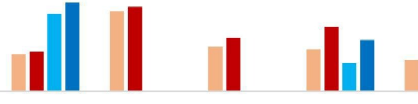

ELIXA PIONNER 6 EMPAREG

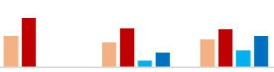

VERTIS
CANVAS a
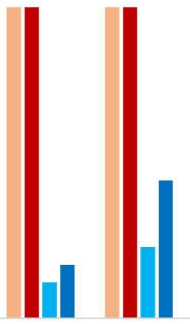
DAPA-HF EMPEROR DAPA-CKD CREDENCE
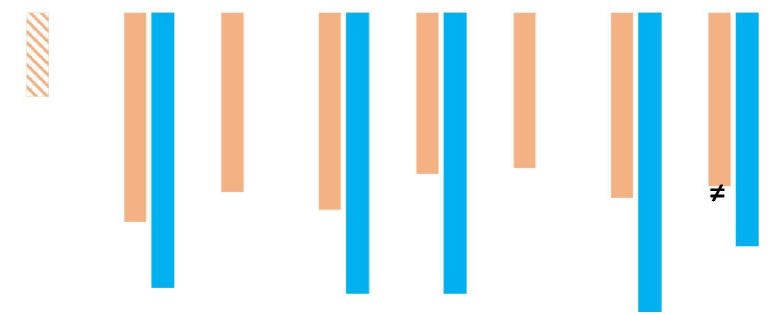

Non Significant Relative Risk Reduction for hHF

N Non Significant Relative Risk Reduction for worsening nephropathy 


\section{Pro-inflammatory state}

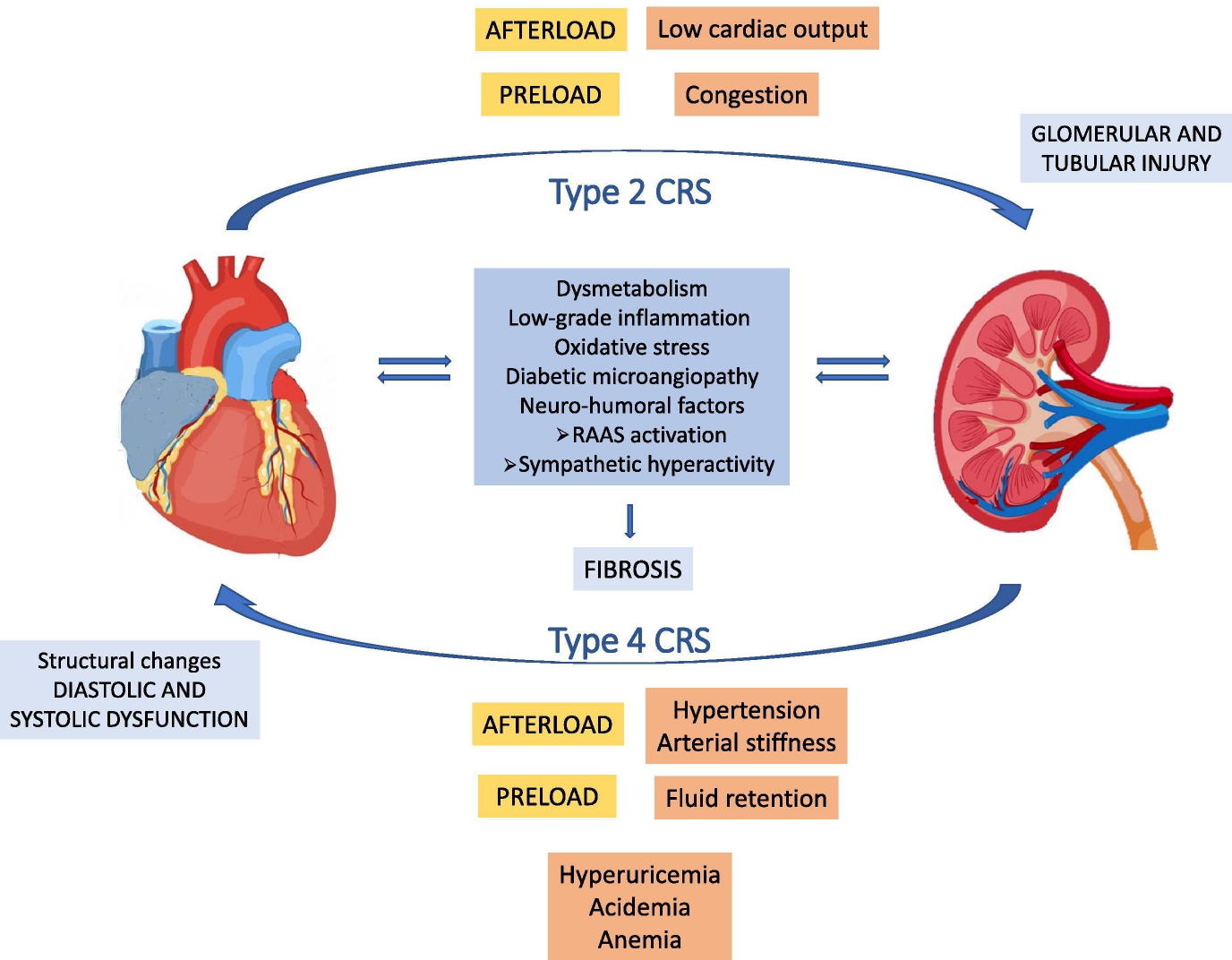



Table 1

Table 1. Management of a patient with diabetes, $\underline{\mathrm{CKD}}$ and/or HF.

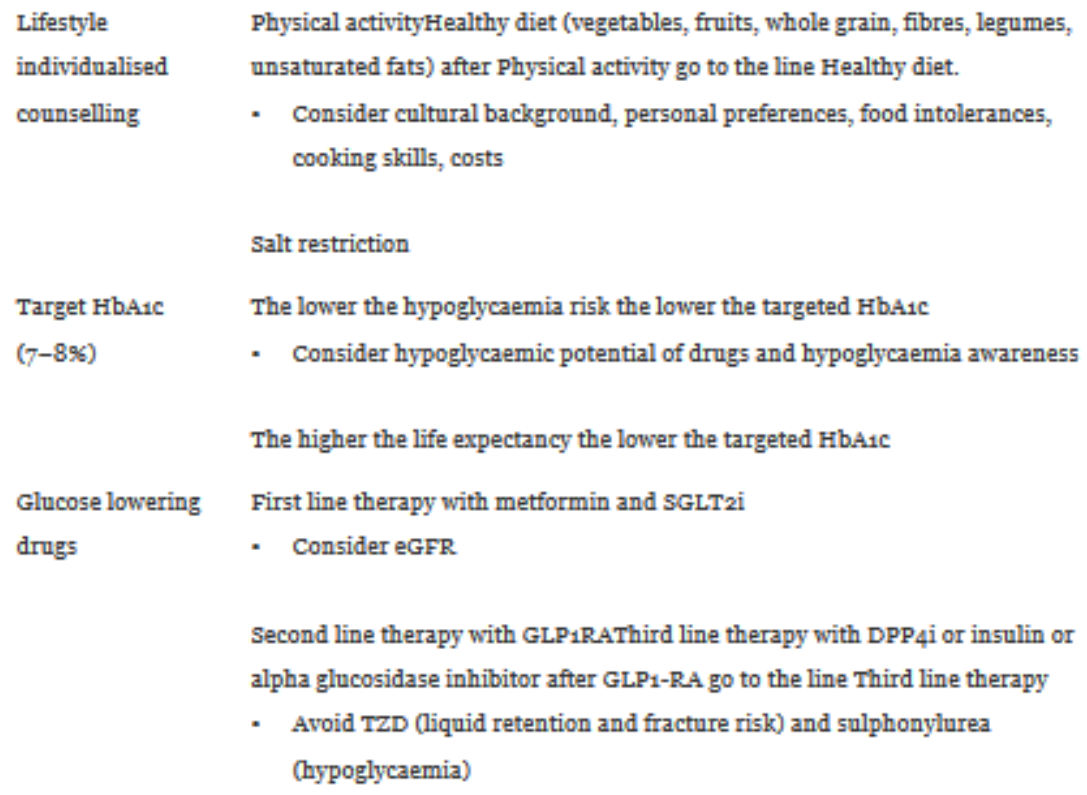

Ref. [61]. 
Table 2

Table 2. The maximal daily dose of metformin and SGLT2is (a) and GLP1-RAs (b) according to renal function (European Medicines Agency summary of products characteristics).

$\mathbf{a}$

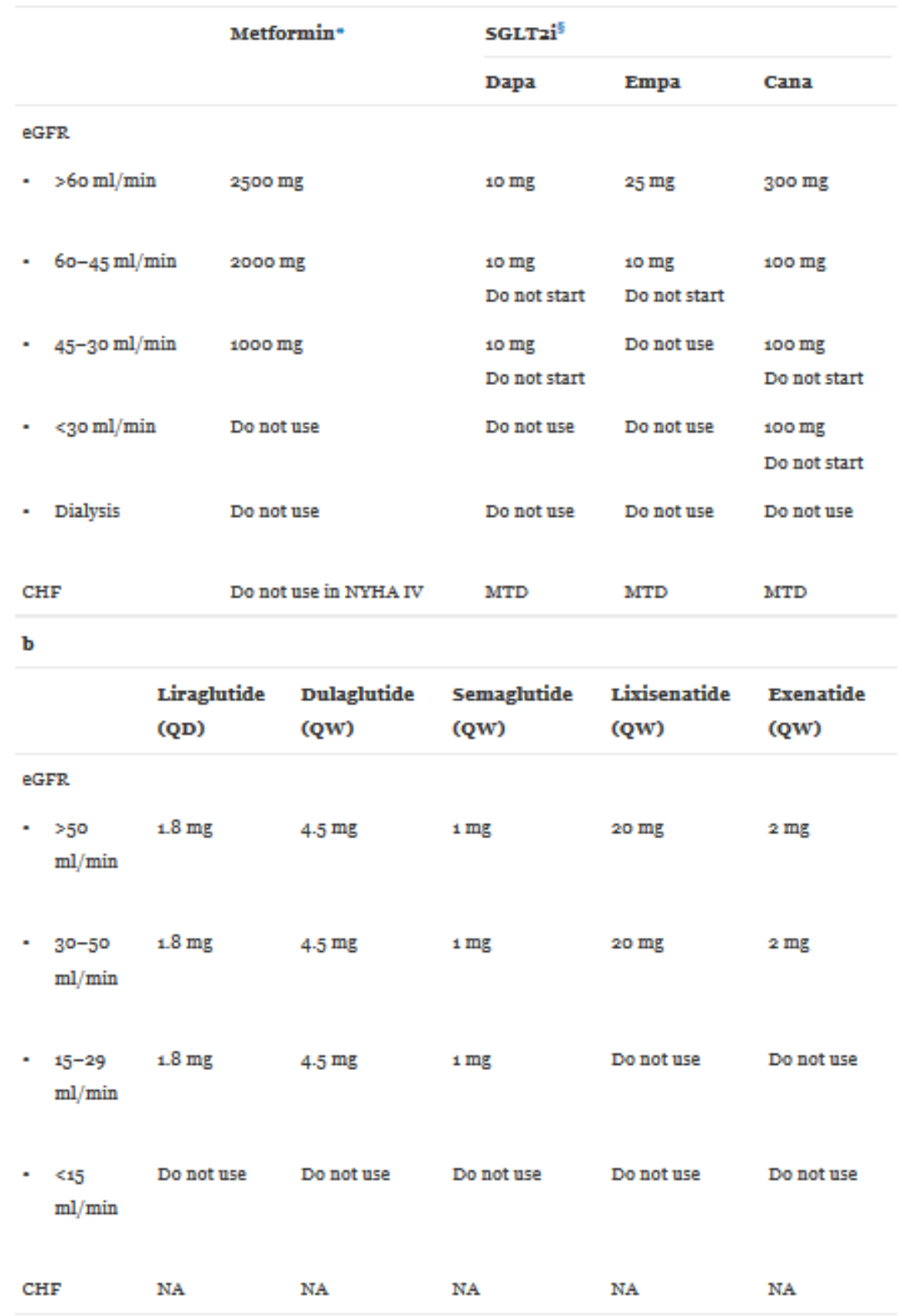

CHF: congestive heart failure. eGFR: estimated glomerular filtration rate. $\mathrm{MTD}=$ maximal tolerated dose.

Ref. [109].

ฐ

Ref. [142]. 


\section{REFERENCES}

[1] Birkeland KI, Bodegard J, Eriksson JW, Norhammar A, Haller H, Linssen GCM, et al. Heart failure and chronic kidney disease manifestation and mortality risk associations in type 2 diabetes: A large multinational cohort study. Diabetes, Obes Metab 2020;22:1607-18. https://doi.org/10.1111/dom.14074.

[2] de Boer IH, Caramori ML, Chan JCN, Heerspink HJL, Hurst C, Khunti K, et al. KDIGO 2020 Clinical Practice Guideline for Diabetes Management in Chronic Kidney Disease. Kidney Int 2020;98:S1-115. https://doi.org/10.1016/j.kint.2020.06.019.

[3] Nichols GA, Hillier TA, Erbey JR, Brown JB. Congestive Heart Failure in Type 2 Diabetes: Prevalence, incidence, and risk factors. Diabetes Care 2001;24:1614-9. https://doi.org/10.2337/diacare.24.9.1614.

[4] Scirica BM, Braunwald E, Raz I, Cavender MA, Morrow DA, Jarolim P, et al. Heart Failure, Saxagliptin, and Diabetes Mellitus: Observations from the SAVOR-TIMI 53 Randomized Trial. Circulation 2014;130:1579-88. https://doi.org/10.1161/CIRCULATIONAHA.114.010389.

[5] Adler AI. Association of systolic blood pressure with macrovascular and microvascular complications of type 2 diabetes (UKPDS 36): prospective observational study. BMJ 2000;321:412-9. https://doi.org/10.1136/bmj.321.7258.412.

[6] Stratton IM. Association of glycaemia with macrovascular and microvascular complications of type 2 diabetes (UKPDS 35): prospective observational study. BMJ 2000;321:405-12. https://doi.org/10.1136/bmj.321.7258.405.

[7] Rawshani A, Rawshani A, Franzén S, Sattar N, Eliasson B, Svensson A-M, et al. Risk Factors, Mortality, and Cardiovascular Outcomes in Patients with Type 2 Diabetes. N Engl J Med 2018;379:633-44. https://doi.org/10.1056/NEJMoa1800256.

[8] Kristensen SL, Preiss D, Jhund PS, Squire I, Cardoso JS, Merkely B, et al. Risk Related to PreDiabetes Mellitus and Diabetes Mellitus in Heart Failure With Reduced Ejection Fraction. Circ Hear Fail 2016;9. https://doi.org/10.1161/CIRCHEARTFAILURE.115.002560.

[9] Zannad F, Ferreira JP, Pocock SJ, Anker SD, Butler J, Filippatos G, et al. SGLT2 inhibitors in patients with heart failure with reduced ejection fraction: a meta-analysis of the EMPEROR-Reduced and DAPA-HF trials. Lancet 2020. https://doi.org/10.1016/S0140-6736(20)31824-9.

[10] Lund LH, Donal E, Oger E, Hage C, Persson H, Haugen-Löfman I, et al. Association between cardiovascular vs. non-cardiovascular co-morbidities and outcomes in heart failure with preserved ejection fraction. Eur J Heart Fail 2014;16:992-1001. https://doi.org/10.1002/ejhf.137.

[11] Guglin M, Lynch K, Krischer J. Heart Failure as a Risk Factor for Diabetes Mellitus. Cardiology 
2014;129:84-92. https://doi.org/10.1159/000363282.

[12] Inzucchi SE, Docherty KF, Køber L, Kosiborod MN, Martinez FA, Ponikowski P, et al. Dapagliflozin and the Incidence of Type 2 Diabetes in Patients With Heart Failure and Reduced Ejection Fraction: An Exploratory Analysis From DAPA-HF. Diabetes Care 2021;44:586-94. https://doi.org/10.2337/dc20-1675.

[13] Gerstein HC. Albuminuria and Risk of Cardiovascular Events, Death, and Heart Failure in Diabetic and Nondiabetic Individuals. JAMA 2001;286:421. https://doi.org/10.1001/jama.286.4.421.

[14] Nayor M, Larson MG, Wang N, Santhanakrishnan R, Lee DS, Tsao CW, et al. The association of chronic kidney disease and microalbuminuria with heart failure with preserved vs. reduced ejection fraction. Eur J Heart Fail 2017;19:615-23. https://doi.org/10.1002/ejhf.778.

[15] Adams KF, Fonarow GC, Emerman CL, LeJemtel TH, Costanzo MR, Abraham WT, et al. Characteristics and outcomes of patients hospitalized for heart failure in the United States: Rationale, design, and preliminary observations from the first 100,000 cases in the Acute Decompensated Heart Failure National Registry (ADHERE). Am Heart J 2005;149:209-16. https://doi.org/10.1016/j.ahj.2004.08.005.

[16] Hillege HL, Nitsch D, Pfeffer MA, Swedberg K, McMurray JJV, Yusuf S, et al. Renal Function as a Predictor of Outcome in a Broad Spectrum of Patients With Heart Failure. Circulation 2006;113:6718. https://doi.org/10.1161/CIRCULATIONAHA.105.580506.

[17] McMurray JJV, Solomon SD, Inzucchi SE, Køber L, Kosiborod MN, Martinez FA, et al. Dapagliflozin in Patients with Heart Failure and Reduced Ejection Fraction. N Engl J Med 2019. https://doi.org/10.1056/nejmoa1911303.

[18] Packer M, Anker SD, Butler J, Filippatos G, Pocock SJ, Carson P, et al. Cardiovascular and Renal Outcomes with Empagliflozin in Heart Failure. N Engl J Med 2020;383:1413-24. https://doi.org/10.1056/NEJMoa2022190.

[19] Zinman B, Wanner C, Lachin JM, Fitchett D, Bluhmki E, Hantel S, et al. Empagliflozin, Cardiovascular Outcomes, and Mortality in Type 2 Diabetes. N Engl J Med 2015;373:2117-28. https://doi.org/10.1056/NEJMoa1504720.

[20] Neal B, Perkovic V, Mahaffey KW, de Zeeuw D, Fulcher G, Erondu N, et al. Canagliflozin and Cardiovascular and Renal Events in Type 2 Diabetes. N Engl J Med 2017;377:644-57. https://doi.org/10.1056/NEJMoa1611925.

[21] Wiviott SD, Raz I, Bonaca MP, Mosenzon O, Kato ET, Cahn A, et al. Dapagliflozin and Cardiovascular Outcomes in Type 2 Diabetes. N Engl J Med 2019;380:347-57. https://doi.org/10.1056/NEJMoa1812389. 
[22] Cannon CP, Pratley R, Dagogo-Jack S, Mancuso J, Huyck S, Masiukiewicz U, et al. Cardiovascular Outcomes with Ertugliflozin in Type 2 Diabetes. N Engl J Med 2020;383:1425-35. https://doi.org/10.1056/NEJMoa2004967.

[23] Heerspink HJL, Stefánsson B V., Correa-Rotter R, Chertow GM, Greene T, Hou F-F, et al. Dapagliflozin in Patients with Chronic Kidney Disease. N Engl J Med 2020. https://doi.org/10.1056/nejmoa2024816.

[24] Perkovic V, Jardine MJ, Neal B, Bompoint S, Heerspink HJL, Charytan DM, et al. Canagliflozin and Renal Outcomes in Type 2 Diabetes and Nephropathy. N Engl J Med 2019;380:2295-306. https://doi.org/10.1056/NEJMoa1811744.

[25] A.F. H, J.B. G, S. J, R.B. D, C.B. G, N.P. J, et al. Albiglutide and cardiovascular outcomes in patients with type 2 diabetes and cardiovascular disease (Harmony Outcomes): a double-blind, randomised placebo-controlled trial. Lancet 2018.

[26] Holman RR, Bethel MA, Mentz RJ, Thompson VP, Lokhnygina Y, Buse JB, et al. Effects of OnceWeekly Exenatide on Cardiovascular Outcomes in Type 2 Diabetes. N Engl J Med 2017;377:1228 39. https://doi.org/10.1056/NEJMoa1612917.

[27] Husain M, Birkenfeld AL, Donsmark M, Dungan K, Eliaschewitz FG, Franco DR, et al. Oral Semaglutide and Cardiovascular Outcomes in Patients with Type 2 Diabetes. N Engl J Med 2019. https://doi.org/10.1056/nejmoa1901118.

[28] Marso SP, Daniels G, Brown-Frandsen K, Kristensen P, Mann J, Nauck M, et al. Liraglutide and Cardiovascular Outcomes in Type 2 Diabetes. N Engl J Med 2016;375:311-22. https://doi.org/10.1056/NEJMoa1603827.Liraglutide.

[29] Gerstein HC, Colhoun HM, Dagenais GR, Diaz R, Lakshmanan M, Pais P, et al. Dulaglutide and cardiovascular outcomes in type 2 diabetes (REWIND): a double-blind, randomised placebocontrolled trial. Lancet 2019. https://doi.org/10.1016/S0140-6736(19)31149-3.

[30] Pfeffer MA, Claggett B, Diaz R, Dickstein K, Gerstein HC, Køber L V., et al. Lixisenatide in Patients with Type 2 Diabetes and Acute Coronary Syndrome. N Engl J Med 2015. https://doi.org/10.1056/nejmoa1509225.

[31] Wheeler DC, Stefánsson B V., Jongs N, Chertow GM, Greene T, Hou FF, et al. Effects of dapagliflozin on major adverse kidney and cardiovascular events in patients with diabetic and nondiabetic chronic kidney disease: a prespecified analysis from the DAPA-CKD trial. Lancet Diabetes Endocrinol 2021;9:22-31. https://doi.org/10.1016/S2213-8587(20)30369-7.

[32] George LK, Koshy SKG, Molnar MZ, Thomas F, Lu JL, Kalantar-Zadeh K, et al. Heart Failure Increases the Risk of Adverse Renal Outcomes in Patients With Normal Kidney Function. Circ Hear 
Fail 2017;10. https://doi.org/10.1161/CIRCHEARTFAILURE.116.003825.

[33] Forman DE, Butler J, Wang Y, Abraham WT, O'Connor CM, Gottlieb SS, et al. Incidence, Predictors at Admission, and Impact of Worsening Renal Function among Patients Hospitalized with Heart Failure. J Am Coll Cardiol 2004. https://doi.org/10.1016/j.jacc.2003.07.031.

[34] Pinier C, Gatault P, Fauchier L, Angoulvant D, François M, Barbet C, et al. Specific impact of past and new major cardiovascular events on acute kidney injury and end-stage renal disease risks in diabetes: a dynamic view. Clin Kidney J 2020;13:17-23. https://doi.org/10.1093/ckj/sfz028.

[35] Anker SD, Butler J, Filippatos G, Khan MS, Marx N, Lam CSP, et al. Effect of Empagliflozin on Cardiovascular and Renal Outcomes in Patients With Heart Failure by Baseline Diabetes Status. Circulation 2021;143:337-49. https://doi.org/10.1161/CIRCULATIONAHA.120.051824.

[36] Tonelli M, Muntner P, Lloyd A, Manns BJ, Klarenbach S, Pannu N, et al. Risk of coronary events in people with chronic kidney disease compared with those with diabetes: A population-level cohort study. Lancet 2012. https://doi.org/10.1016/S0140-6736(12)60572-8.

[37] Valensi P, Paries J, Brulport-Cerisier V, Torremocha F, Sachs R-N, Vanzetto G, et al. Predictive Value of Silent Myocardial Ischemia for Cardiac Events in Diabetic Patients: Influence of age in a French multicenter study. Diabetes Care 2005;28:2722-7. https://doi.org/10.2337/diacare.28.11.2722.

[38] Valensi P, Henry P, Boccara F, Cosson E, Prevost G, Emmerich J, et al. Risk stratification and screening for coronary artery disease in asymptomatic patients with diabetes mellitus: Position paper of the French Society of Cardiology and the French-speaking Society of Diabetology. Diabetes Metab 2021;47:101185. https://doi.org/10.1016/j.diabet.2020.08.002.

[39] Valensi P, Meune C. Congestive heart failure caused by silent ischemia and silent myocardial infarction. Herz 2019;44:210-7. https://doi.org/10.1007/s00059-019-4798-3.

[40] Soliman EZ. Silent myocardial infarction and risk of heart failure: Current evidence and gaps in knowledge. Trends Cardiovasc Med 2019;29:239-44. https://doi.org/10.1016/j.tcm.2018.09.004.

[41] He J, Reilly M, Yang W, Chen J, Go AS, Lash JP, et al. Risk Factors for Coronary Artery Calcium Among Patients With Chronic Kidney Disease (from the Chronic Renal Insufficiency Cohort Study). Am J Cardiol 2012;110:1735-41. https://doi.org/10.1016/j.amjcard.2012.07.044.

[42] Pham I, Cosson E, Nguyen MT, Banu I, Genevois I, Poignard P, et al. Evidence for a specific diabetic cardiomyopathy: An observational retrospective echocardiographic study in 656 asymptomatic type 2 diabetic patients. Int J Endocrinol 2015. https://doi.org/10.1155/2015/743503.

[43] Arnold S V., Khunti K, Bonnet F, Charbonnel B, Chen H, Cid-Ruzafa J, et al. Type 2 diabetes and heart failure: insights from the global DISCOVER study. ESC Hear Fail 2021;8:1711-6. https://doi.org/10.1002/ehf2.13235. 
[44] Nitenberg A, Valensi P, Sachs R, Dali M, Aptecar E, Attali J-R. Impairment of Coronary Vascular Reserve and ACh-Induced Coronary Vasodilation in Diabetic Patients With Angiographically Normal Coronary Arteries and Normal Left Ventricular Systolic Function. Diabetes 1993;42:1017-25. https://doi.org/10.2337/diab.42.7.1017.

[45] Baldassarre S, Fragapani S, Panero A, Fedele D, Pinach S, Lucchiari M, et al. NTproBNP in insulinresistance mediated conditions: overweight/obesity, metabolic syndrome and diabetes. The population-based Casale Monferrato Study. Cardiovasc Diabetol 2017;16:119. https://doi.org/10.1186/s12933-017-0601-z.

[46] Dandamudi S, Slusser J, Mahoney DW, Redfield MM, Rodeheffer RJ, Chen HH. The Prevalence of Diabetic Cardiomyopathy: A Population-Based Study in Olmsted County, Minnesota. J Card Fail 2014;20:304-9. https://doi.org/10.1016/j.cardfail.2014.02.007.

[47] Nguyen MT, Cosson E, Valensi P, Poignard P, Nitenberg A, Pham I. Transthoracic echocardiographic abnormalities in asymptomatic diabetic patients: Association with microalbuminuria and silent coronary artery disease. Diabetes Metab 2011. https://doi.org/10.1016/j.diabet.2010.12.006.

[48] Kopp UC. Role of renal sensory nerves in physiological and pathophysiological conditions. Am J Physiol Integr Comp Physiol 2015;308:R79-95. https://doi.org/10.1152/ajpregu.00351.2014.

[49] Singh DK, Winocour P, Farrington K. Mechanisms of Disease: The hypoxic tubular hypothesis of diabetic nephropathy. Nat Clin Pract Nephrol 2008. https://doi.org/10.1038/ncpneph0757.

[50] Spallone V, Valensi P. SGLT2 inhibitors and the autonomic nervous system in diabetes: A promising challenge to better understand multiple target improvement. Diabetes Metab 2021;47:101224. https://doi.org/10.1016/j.diabet.2021.101224.

[51] Cops J, Mullens W, Verbrugge FH, Swennen Q, De Moor B, Reynders C, et al. Selective abdominal venous congestion induces adverse renal and hepatic morphological and functional alterations despite a preserved cardiac function. Sci Rep 2018;8:17757. https://doi.org/10.1038/s41598-018-36189-3.

[52] Damman K, Ng Kam Chuen MJ, MacFadyen RJ, Lip GYH, Gaze D, Collinson PO, et al. Volume Status and Diuretic Therapy in Systolic Heart Failure and the Detection of Early Abnormalities in Renal and Tubular Function. J Am Coll Cardiol 2011;57:2233-41. https://doi.org/10.1016/j.jacc.2010.10.065.

[53] Mullens W, Abrahams Z, Francis GS, Sokos G, Taylor DO, Starling RC, et al. Importance of Venous Congestion for Worsening of Renal Function in Advanced Decompensated Heart Failure. J Am Coll Cardiol 2009. https://doi.org/10.1016/j.jacc.2008.05.068.

[54] Shimada S, Hirose T, Takahashi C, Sato E, Kinugasa S, Ohsaki Y, et al. Pathophysiological and 
molecular mechanisms involved in renal congestion in a novel rat model. Sci Rep 2018;8:16808. https://doi.org/10.1038/s41598-018-35162-4.

[55] Ronco C, Haapio M, House AA, Anavekar N, Bellomo R. Cardiorenal Syndrome. J Am Coll Cardiol 2008;52:1527-39. https://doi.org/10.1016/j.jacc.2008.07.051.

[56] Schefold JC, Filippatos G, Hasenfuss G, Anker SD, von Haehling S. Heart failure and kidney dysfunction: epidemiology, mechanisms and management. Nat Rev Nephrol 2016;12:610-23. https://doi.org/10.1038/nrneph.2016.113.

[57] Eckardt K-U, Bansal N, Coresh J, Evans M, Grams ME, Herzog CA, et al. Improving the prognosis of patients with severely decreased glomerular filtration rate (CKD G4+): conclusions from a Kidney Disease: Improving Global Outcomes (KDIGO) Controversies Conference. Kidney Int 2018;93:1281-92. https://doi.org/10.1016/j.kint.2018.02.006.

[58] Jentzer JC, Bihorac A, Brusca SB, Del Rio-Pertuz G, Kashani K, Kazory A, et al. Contemporary Management of Severe Acute Kidney Injury and Refractory Cardiorenal Syndrome. J Am Coll Cardiol 2020;76:1084-101. https://doi.org/10.1016/j.jacc.2020.06.070.

[59] Boonman-de Winter LJM, Rutten FH, Cramer MJM, Landman MJ, Liem AH, Rutten GEHM, et al. High prevalence of previously unknown heart failure and left ventricular dysfunction in patients with type 2 diabetes. Diabetologia 2012;55:2154-62. https://doi.org/10.1007/s00125-012-2579-0.

[60] Wang Y, Yang H, Huynh Q, Nolan M, Negishi K, Marwick TH. Diagnosis of Nonischemic Stage B Heart Failure in Type 2 Diabetes Mellitus: Optimal Parameters for Prediction of Heart Failure. JACC Cardiovasc Imaging 2018. https://doi.org/10.1016/j.jcmg.2018.03.015.

[61] Cosentino F, Grant PJ, Aboyans V, Bailey CJ, Ceriello A, Delgado V, et al. 2019 ESC Guidelines on diabetes, pre-diabetes, and cardiovascular diseases developed in collaboration with the EASD. Eur Heart J 2020;41:255-323. https://doi.org/10.1093/eurheartj/ehz486.

[62] Cannistraci R, Mazzetti S, Mortara A, Perseghin G, Ciardullo S. Risk stratification tools for heart failure in the diabetes clinic. Nutr Metab Cardiovasc Dis 2020;30:1070-9. https://doi.org/10.1016/j.numecd.2020.03.022.

[63] Berg DD, Wiviott SD, Scirica BM, Gurmu Y, Mosenzon O, Murphy SA, et al. Heart Failure Risk Stratification and Efficacy of Sodium-Glucose Cotransporter-2 Inhibitors in Patients With Type 2 Diabetes Mellitus. Circulation 2019;140:1569-77. https://doi.org/10.1161/CIRCULATIONAHA.119.042685.

[64] Butler J, Kalogeropoulos A, Georgiopoulou V, Belue R, Rodondi N, Garcia M, et al. Incident Heart Failure Prediction in the Elderly. Circ Hear Fail 2008;1:125-33. https://doi.org/10.1161/CIRCHEARTFAILURE.108.768457. 
[65] Fitchett D, Butler J, van de Borne P, Zinman B, Lachin JM, Wanner C, et al. Effects of empagliflozin on risk for cardiovascular death and heart failure hospitalization across the spectrum of heart failure risk in the EMPA-REG OUTCOME® trial. Eur Heart J 2018;39:363-70. https://doi.org/10.1093/eurheartj/ehx511.

[66] Mordi IR, Tee A, Palmer CN, McCrimmon RJ, Doney ASF, Lang CC. Microvascular disease and heart failure with reduced and preserved ejection fraction in type 2 diabetes. ESC Hear Fail 2020;7:1168-77. https://doi.org/10.1002/ehf2.12669.

[67] Verma S, Wanner C, Zwiener I, Ofstad AP, George JT, Fitchett D, et al. Influence of Microvascular Disease on Cardiovascular Events in Type 2 Diabetes. J Am Coll Cardiol 2019;73:2780-2. https://doi.org/10.1016/j.jacc.2019.03.002.

[68] Arrigo M, Cippà PE, Mebazaa A. Cardiorenal Interactions Revisited: How to Improve Heart Failure Outcomes in Patients With Chronic Kidney Disease. Curr Heart Fail Rep 2018. https://doi.org/10.1007/s11897-018-0406-8.

[69] Tadic M, Suzic-Lazic J, Vukomanovic V, Cuspidi C, Ilic S, Celic V. Functional capacity and left ventricular diastolic function in patients with type 2 diabetes. Acta Diabetol 2021;58:107-13. https://doi.org/10.1007/s00592-020-01600-x.

[70] Parrinello G, Greene SJ, Torres D, Alderman M, Bonventre JV, Di Pasquale P, et al. Water and Sodium in Heart Failure: A Spotlight on Congestion. Heart Fail Rev 2015. https://doi.org/10.1007/s10741-014-9438-7.

[71] Huelsmann M, Neuhold S, Strunk G, Moertl D, Berger R, Prager R, et al. NT-proBNP has a high negative predictive value to rule-out short-term cardiovascular events in patients with diabetes mellitus. Eur Heart J 2008. https://doi.org/10.1093/eurheartj/ehn334.

[72] Luchner A, Hengstenberg C, Löwel H, Riegger GAJ, Schunkert H, Holmer S. Effect of Compensated Renal Dysfunction on Approved Heart Failure Markers. Hypertension 2005;46:118-23. https://doi.org/10.1161/01.HYP.0000170140.36633.8f.

[73] Bansal N, Zelnick L, Go A, Anderson A, Christenson R, Deo R, et al. Cardiac Biomarkers and Risk of Incident Heart Failure in Chronic Kidney Disease: The CRIC (Chronic Renal Insufficiency Cohort) Study. J Am Heart Assoc 2019;8. https://doi.org/10.1161/JAHA.119.012336.

[74] Saulnier P-J, Gand E, Velho G, Mohammedi K, Zaoui P, Fraty M, et al. Association of Circulating Biomarkers (Adrenomedullin, TNFR1, and NT-proBNP) With Renal Function Decline in Patients With Type 2 Diabetes: A French Prospective Cohort. Diabetes Care 2017;40:367-74. https://doi.org/10.2337/dc16-1571.

[75] Fraty M, Velho G, Gand E, Fumeron F, Ragot S, Sosner P, et al. Prognostic value of plasma MR- 
proADM vs NT-proBNP for heart failure in people with type 2 diabetes: the SURDIAGENE prospective study. Diabetologia 2018. https://doi.org/10.1007/s00125-018-4727-7.

[76] House AA, Wanner C, Sarnak MJ, Piña IL, McIntyre CW, Komenda P, et al. Heart failure in chronic kidney disease: conclusions from a Kidney Disease: Improving Global Outcomes (KDIGO) Controversies Conference. Kidney Int 2019;95:1304-17. https://doi.org/10.1016/j.kint.2019.02.022.

[77] McCallum W, Tighiouart H, Testani JM, Griffin M, Konstam MA, Udelson JE, et al. Association of Volume Overload With Kidney Function Outcomes Among Patients With Heart Failure With Reduced Ejection Fraction. Kidney Int Reports 2020;5:1661-9. https://doi.org/10.1016/j.ekir.2020.07.015.

[78] Bansal N, Katz R, Dalrymple L, de Boer I, DeFilippi C, Kestenbaum B, et al. NT-ProBNP and Troponin T and Risk of Rapid Kidney Function Decline and Incident CKD in Elderly Adults. Clin J Am Soc Nephrol 2015;10:205-14. https://doi.org/10.2215/CJN.04910514.

[79] Park M, Vittinghoff E, Shlipak MG, Mishra R, Whooley M, Bansal N. Associations of N-terminal pro-B-type natriuretic peptide with kidney function decline in persons without clinical heart failure in the Heart and Soul Study. Am Heart J 2014;168:931-939.e2. https://doi.org/10.1016/j.ahj.2014.09.008.

[80] Kosmala W, O’Moore-Sullivan T, Plaksej R, Przewlocka-Kosmala M, Marwick TH. Improvement of left ventricular function by lifestyle intervention in obesity: contributions of weight loss and reduced insulin resistance. Diabetologia 2009;52:2306-16. https://doi.org/10.1007/s00125-009-1507-4.

[81] Oliveras A, Molina L, Goday A, Sans L, Riera M, Vazquez S, et al. Effect of bariatric surgery on cardiac structure and function in obese patients: Role of the renin-angiotensin system. J Clin Hypertens 2021;23:181-92. https://doi.org/10.1111/jch.14129.

[82] Pandey A, Patel K V., Bahnson JL, Gaussoin SA, Martin CK, Balasubramanyam A, et al. Association of Intensive Lifestyle Intervention, Fitness, and Body Mass Index With Risk of Heart Failure in Overweight or Obese Adults With Type 2 Diabetes Mellitus. Circulation 2020;141:1295-306. https://doi.org/10.1161/CIRCULATIONAHA.119.044865.

[83] Bahnson JL, Knowler WC, Bantle JP, Bertoni AG, Bray GA, Chen H, et al. Effect of a long-term behavioural weight loss intervention on nephropathy in overweight or obese adults with type 2 diabetes: A secondary analysis of the Look AHEAD randomised clinical trial. Lancet Diabetes Endocrinol 2014. https://doi.org/10.1016/S2213-8587(14)70156-1.

[84] Kitzman DW, Brubaker P, Morgan T, Haykowsky M, Hundley G, Kraus WE, et al. Effect of Caloric Restriction or Aerobic Exercise Training on Peak Oxygen Consumption and Quality of Life in Obese Older Patients With Heart Failure With Preserved Ejection Fraction. JAMA 2016;315:36. 
https://doi.org/10.1001/jama.2015.17346.

[85] Praga M, Hernandez E, Herrero JC, Morales E, Revilla Y, Diaz-Gonzalez R, et al. Influence of obesity on the appearance of proteinuria and renal insufficiency after unilateral nephrectomy. Kidney Int 2000;58:2111-8. https://doi.org/10.1046/j.1523-1755.2000.00384.x.

[86] Shulman A, Andersson-Assarsson JC, Sjöström CD, Jacobson P, Taube M, Sjöholm K, et al. Remission and progression of pre-existing micro- and macroalbuminuria over 15 years after bariatric surgery in Swedish Obese Subjects study. Int J Obes 2021;45:535-46. https://doi.org/10.1038/s41366-020-00707-z.

[87] Guggino J, Coumes S, Wion N, Reche F, Arvieux C, Borel A-L. Effectiveness and Safety of Bariatric Surgery in Patients with End-Stage Chronic Kidney Disease or Kidney Transplant. Obesity 2020;28:2290-304. https://doi.org/10.1002/oby.23001.

[88] Castagno D, Baird-Gunning J, Jhund PS, Biondi-Zoccai G, MacDonald MR, Petrie MC, et al. Intensive glycemic control has no impact on the risk of heart failure in type 2 diabetic patients: Evidence from a 37,229 patient meta-analysis. Am Heart J 2011;162:938-948.e2. https://doi.org/10.1016/j.ahj.2011.07.030.

[89] Turner R. Intensive blood-glucose control with sulphonylureas or insulin compared with conventional treatment and risk of complications in patients with type 2 diabetes (UKPDS 33). Lancet 1998;352:837-53. https://doi.org/10.1016/S0140-6736(98)07019-6.

[90] De Boer IH. Kidney disease and related findings in the diabetes control and complications trial/ epidemiology of diabetes interventions and complications study. Diabetes Care 2014. https://doi.org/10.2337/dc13-2113.

[91] Emdin CA, Rahimi K, Neal B, Callender T, Perkovic V, Patel A. Blood Pressure Lowering in Type 2 Diabetes. JAMA 2015;313:603. https://doi.org/10.1001/jama.2014.18574.

[92] Cholesterol Treatment Trialists' (CTT) Collaboration, Fulcher J, O’Connell R, Voysey M, Emberson JBlackwell L et al. Efficacy and Safety of LDL-Lowering Therapy Among Men and Women: MetaAnalysis of Individual Data From 174,000 Participants in 27 Randomized Trials. J Vasc Surg 2015. https://doi.org/10.1016/j.jvs.2015.07.047.

[93] Lee MMY, Sattar N, McMurray JJ V., Packard CJ. Statins in the Prevention and Treatment of Heart Failure: a Review of the Evidence. Curr Atheroscler Rep 2019;21:41. https://doi.org/10.1007/s11883019-0800-z.

[94] Zhu L, Hayen A, Bell KJL. Legacy effect of fibrate add-on therapy in diabetic patients with dyslipidemia: a secondary analysis of the ACCORDION study. Cardiovasc Diabetol 2020;19:28. https://doi.org/10.1186/s12933-020-01002-x. 
[95] Papademetriou V, Lovato L, Tsioufis C, Cushman W, Applegate WB, Mottle A, et al. Effects of High Density Lipoprotein Raising Therapies on Cardiovascular Outcomes in Patients with Type 2 Diabetes Mellitus, with or without Renal Impairment: The Action to Control Cardiovascular Risk in Diabetes Study. Am J Nephrol 2017;45:136-45. https://doi.org/10.1159/000453626.

[96] Frazier R, Mehta R, Cai X, Lee J, Napoli S, Craven T, et al. Associations of Fenofibrate Therapy With Incidence and Progression of CKD in Patients With Type 2 Diabetes. Kidney Int Reports 2019;4:94-102. https://doi.org/10.1016/j.ekir.2018.09.006.

[97] Katsiki N, Mikhailidis DP, Banach M. Lipid-lowering agents for concurrent cardiovascular and chronic kidney disease. Expert Opin Pharmacother 2019;20:2007-17. https://doi.org/10.1080/14656566.2019.1649394.

[98] Oellgaard J, Gæde P, Rossing P, Rørth R, Køber L, Parving HH, et al. Reduced risk of heart failure with intensified multifactorial intervention in individuals with type 2 diabetes and microalbuminuria: 21 years of follow-up in the randomised Steno-2 study. Diabetologia 2018. https://doi.org/10.1007/s00125-018-4642-y.

[99] Oellgaard J, Gæde P, Rossing P, Persson F, Parving H-H, Pedersen O. Intensified multifactorial intervention in type 2 diabetics with microalbuminuria leads to long-term renal benefits. Kidney Int 2017;91:982-8. https://doi.org/10.1016/j.kint.2016.11.023.

[100] Brenner BM, Cooper ME, de Zeeuw D, Keane WF, Mitch WE, Parving H-H, et al. Effects of Losartan on Renal and Cardiovascular Outcomes in Patients with Type 2 Diabetes and Nephropathy. N Engl J Med 2001;345:861-9. https://doi.org/10.1056/NEJMoa011161.

[101] Lewis EJ, Hunsicker LG, Clarke WR, Berl T, Pohl MA, Lewis JB, et al. Renoprotective Effect of the Angiotensin-Receptor Antagonist Irbesartan in Patients with Nephropathy Due to Type 2 Diabetes. N Engl J Med 2001. https://doi.org/10.1056/nejmoa011303.

[102] Strippoli GFM, Bonifati C, Craig ME, Navaneethan SD, Craig JC. Angiotensin converting enzyme inhibitors and angiotensin II receptor antagonists for preventing the progression of diabetic kidney disease. Cochrane Database Syst Rev 2006. https://doi.org/10.1002/14651858.CD006257.

[103] Marx N, Floege J. Heart failure in advanced chronic kidney disease: treatment rationaleHerzinsuffizienz bei fortgeschrittener Niereninsuffizienz: Grundprinzip der Behandlung. Herz 2021. https://doi.org/10.1007/s00059-021-05024-3.

[104] Palevsky PM, Liu KD, Brophy PD, Chawla LS, Parikh CR, Thakar C V., et al. KDOQI US Commentary on the 2012 KDIGO Clinical Practice Guideline for Acute Kidney Injury. Am J Kidney Dis 2013;61:649-72. https://doi.org/10.1053/j.ajkd.2013.02.349.

[105] Ostermann M, Bellomo R, Burdmann EA, Doi K, Endre ZH, Goldstein SL, et al. Controversies in 
acute kidney injury: conclusions from a Kidney Disease: Improving Global Outcomes (KDIGO) Conference. Kidney Int., 2020. https://doi.org/10.1016/j.kint.2020.04.020.

[106] da Silva AA, do Carmo JM, Li X, Wang Z, Mouton AJ, Hall JE. Role of Hyperinsulinemia and Insulin Resistance in Hypertension: Metabolic Syndrome Revisited. Can J Cardiol 2020;36:671-82. https://doi.org/10.1016/j.cjca.2020.02.066.

[107] Hertzel C Gerstein, Jackie Bosch, Gilles R Dagenais, Rafael Díaz, Hyejung Jung, Aldo P Maggioni, Janice Pogue, Jeffrey Probstfield, Ambady Ramachandran, Matthew C Riddle, Lars E Rydén SYOTI. Basal Insulin and Cardiovascular and Other Outcomes in Dysglycemia. N Engl J Med 2012;367:319_ 28. https://doi.org/10.1056/NEJMoa1203858.

[108] Crowley MJ, Diamantidis CJ, McDuffie JR, Cameron CB, Stanifer JW, Mock CK, et al. Clinical outcomes of metformin use in populations with chronic kidney disease, congestive heart failure, or chronic liver disease: A systematic review. Ann Intern Med 2017;166. https://doi.org/10.7326/M161901.

[109] FDA. FDA Drug Safety Communication: FDA revises warnings regarding use of the diabetes medicine metformin in certain patients with reduced kidney function 2016. http://www.fda.gov/Drugs/DrugSafety/ucm493244.htm (accessed March 30, 2021).

[110] Inzucchi SE, Lipska KJ, Mayo H, Bailey CJ, McGuire DK. Metformin in Patients With Type 2 Diabetes and Kidney Disease. JAMA 2014;312:2668. https://doi.org/10.1001/jama.2014.15298.

[111] Roumie CL, Min JY, D’Agostino McGowan L, Presley C, Grijalva CG, Hackstadt AJ, et al. Comparative Safety of Sulfonylurea and Metformin Monotherapy on the Risk of Heart Failure: A Cohort Study. J Am Heart Assoc 2017;6. https://doi.org/10.1161/JAHA.116.005379.

[112] Erdmann E, Charbonnel B, Wilcox RG, Skene AM, Massi-Benedetti M, Yates J, et al. Pioglitazone Use and Heart Failure in Patients With Type 2 Diabetes and Preexisting Cardiovascular Disease: Data from the PROactive Study (PROactive 08). Diabetes Care 2007;30:2773-8. https://doi.org/10.2337/dc07-0717.

[113] Sarafidis PA, Stafylas PC, Georgianos PI, Saratzis AN, Lasaridis AN. Effect of Thiazolidinediones on Albuminuria and Proteinuria in Diabetes: A Meta-analysis. Am J Kidney Dis 2010;55:835-47. https://doi.org/10.1053/j.ajkd.2009.11.013.

[114] Imano E, Kanda T, Nakatani Y, Nishida T, Arai K, Motomura M, et al. Effect of Troglitazene on Microalbuminuria in Patients With Incipient Diabetic Nephropathy. Diabetes Care 1998;21:2135-9. https://doi.org/10.2337/diacare.21.12.2135.

[115] Nakamura T, Ushiyama C, Suzuki S, Shimada N, Sekizuka K, Ebihara L, et al. Effect of troglitazone on urinary albumin excretion and serum type IV collagen concentrations in Type 2 diabetic patients 
with microalbuminuria or macroalbuminuria. Diabet Med 2001;18:308-13.

https://doi.org/10.1046/j.1464-5491.2001.00463.x.

[116] Meier C, Kraenzlin ME, Bodmer M, Jick SS, Jick H, Meier CR. Use of Thiazolidinediones and Fracture Risk. Arch Intern Med 2008;168:820. https://doi.org/10.1001/archinte.168.8.820.

[117] McGuire DK, Van de Werf F, Armstrong PW, Standl E, Koglin J, Green JB, et al. Association Between Sitagliptin Use and Heart Failure Hospitalization and Related Outcomes in Type 2 Diabetes Mellitus. JAMA Cardiol 2016;1:126. https://doi.org/10.1001/jamacardio.2016.0103.

[118] Scheen AJ. Effects of glucose-lowering agents on surrogate endpoints and hard clinical renal outcomes in patients with type 2 diabetes. Diabetes Metab 2019;45:110-21. https://doi.org/10.1016/j.diabet.2018.10.003.

[119] Kristensen SL, Rørth R, Jhund PS, Docherty KF, Sattar N, Preiss D, et al. Cardiovascular, mortality, and kidney outcomes with GLP-1 receptor agonists in patients with type 2 diabetes: a systematic review and meta-analysis of cardiovascular outcome trials. Lancet Diabetes Endocrinol 2019;7:77685. https://doi.org/10.1016/S2213-8587(19)30249-9.

[120] McGuire DK, Shih WJ, Cosentino F, Charbonnel B, Cherney DZI, Dagogo-Jack S, et al. Association of SGLT2 Inhibitors With Cardiovascular and Kidney Outcomes in Patients With Type 2 Diabetes. JAMA Cardiol 2021;6:148. https://doi.org/10.1001/jamacardio.2020.4511.

[121] Zelniker TA, Wiviott SD, Raz I, Im K, Goodrich EL, Bonaca MP, et al. SGLT2 inhibitors for primary and secondary prevention of cardiovascular and renal outcomes in type 2 diabetes: a systematic review and meta-analysis of cardiovascular outcome trials. Lancet 2019;393:31-9. https://doi.org/10.1016/S0140-6736(18)32590-X.

[122] Cherney DZI, McGuire DK, Charbonnel B, Cosentino F, Pratley R, Dagogo-Jack S, et al. Gradient of Risk and Associations With Cardiovascular Efficacy of Ertugliflozin by Measures of Kidney Function. Circulation 2021. https://doi.org/10.1161/circulationaha.120.051901.

[123] Mahaffey KW, Jardine MJ, Bompoint S, Cannon CP, Neal B, Heerspink HJL, et al. Canagliflozin and Cardiovascular and Renal Outcomes in Type 2 Diabetes Mellitus and Chronic Kidney Disease in Primary and Secondary Cardiovascular Prevention Groups. Circulation 2019;140:739-50. https://doi.org/10.1161/CIRCULATIONAHA.119.042007.

[124] Inzucchi SE, Zinman B, Fitchett D, Wanner C, Ferrannini E, Schumacher M, et al. How Does Empagliflozin Reduce Cardiovascular Mortality? Insights From a Mediation Analysis of the EMPAREG OUTCOME Trial. Diabetes Care 2018;41:356-63. https://doi.org/10.2337/dc17-1096.

[125] Verma S, Garg A, Yan AT, Gupta AK, Al-Omran M, Sabongui A, et al. Effect of Empagliflozin on Left Ventricular Mass and Diastolic Function in Individuals With Diabetes: An Important Clue to the 
EMPA-REG OUTCOME Trial? Diabetes Care 2016;39:e212-3. https://doi.org/10.2337/dc16-1312.

[126] Cooper ME, Inzucchi SE, Zinman B, Hantel S, von Eynatten M, Wanner C, et al. Glucose Control and the Effect of Empagliflozin on Kidney Outcomes in Type 2 Diabetes: An Analysis From the EMPA-REG OUTCOME Trial. Am J Kidney Dis 2019;74:713-5. https://doi.org/10.1053/j.ajkd.2019.03.432.

[127] Kohan DE, Fioretto P, Tang W, List JF. Long-term study of patients with type 2 diabetes and moderate renal impairment shows that dapagliflozin reduces weight and blood pressure but does not improve glycemic control. Kidney Int 2014. https://doi.org/10.1038/ki.2013.356.

[128] Cherney DZI, Perkins BA, Soleymanlou N, Maione M, Lai V, Lee A, et al. Renal Hemodynamic Effect of Sodium-Glucose Cotransporter 2 Inhibition in Patients With Type 1 Diabetes Mellitus. Circulation 2014;129:587-97. https://doi.org/10.1161/CIRCULATIONAHA.113.005081.

[129] van Bommel EJM, Muskiet MHA, van Baar MJB, Tonneijck L, Smits MM, Emanuel AL, et al. The renal hemodynamic effects of the SGLT2 inhibitor dapagliflozin are caused by post-glomerular vasodilatation rather than pre-glomerular vasoconstriction in metformin-treated patients with type 2 diabetes in the randomized, double-blind RED trial. Kidney Int 2020. https://doi.org/10.1016/j.kint.2019.09.013.

[130] Kraus BJ, Weir MR, Bakris GL, Mattheus M, Cherney DZI, Sattar N, et al. Characterization and implications of the initial estimated glomerular filtration rate 'dip' upon sodium-glucose cotransporter-2 inhibition with empagliflozin in the EMPA-REG OUTCOME trial. Kidney Int 2021;99:750-62. https://doi.org/10.1016/j.kint.2020.10.031.

[131] Kogot-Levin A, Hinden L, Riahi Y, Israeli T, Tirosh B, Cerasi E, et al. Proximal Tubule mTORC1 Is a Central Player in the Pathophysiology of Diabetic Nephropathy and Its Correction by SGLT2 Inhibitors. Cell Rep 2020;32:107954. https://doi.org/10.1016/j.celrep.2020.107954.

[132] Bonnet F, Scheen AJ. Effects of SGLT2 inhibitors on systemic and tissue low-grade inflammation: The potential contribution to diabetes complications and cardiovascular disease. Diabetes Metab 2018. https://doi.org/10.1016/j.diabet.2018.09.005.

[133] Bailey CJ. Uric acid and the cardio-renal effects of SGLT2 inhibitors. Diabetes, Obes Metab 2019;21:1291-8. https://doi.org/10.1111/dom.13670.

[134] Abuissa H, Jones PG, Marso SP, O’Keefe JH. Angiotensin-Converting Enzyme Inhibitors or Angiotensin Receptor Blockers for Prevention of Type 2 Diabetes. J Am Coll Cardiol 2005;46:821-6. https://doi.org/10.1016/j.jacc.2005.05.051.

[135] Elliott WJ, Meyer PM. Incident diabetes in clinical trials of antihypertensive drugs: a network metaanalysis. Lancet 2007;369:201-7. https://doi.org/10.1016/S0140-6736(07)60108-1. 
[136] Seferovic JP, Claggett B, Seidelmann SB, Seely EW, Packer M, Zile MR, et al. Effect of sacubitril/valsartan versus enalapril on glycaemic control in patients with heart failure and diabetes: a post-hoc analysis from the PARADIGM-HF trial. Lancet Diabetes Endocrinol 2017;5:333-40. https://doi.org/10.1016/S2213-8587(17)30087-6.

[137] Ikizler TA, Burrowes JD, Byham-Gray LD, Campbell KL, Carrero J-J, Chan W, et al. KDOQI Clinical Practice Guideline for Nutrition in CKD: 2020 Update. Am J Kidney Dis 2020;76:S1-107. https://doi.org/10.1053/j.ajkd.2020.05.006.

[138] Mills KT, Chen J, Yang W, Appel LJ, Kusek JW, Alper A, et al. Sodium Excretion and the Risk of Cardiovascular Disease in Patients With Chronic Kidney Disease. JAMA 2016;315:2200. https://doi.org/10.1001/jama.2016.4447.

[139] Seferovic PM, Ponikowski P, Anker SD, Bauersachs J, Chioncel O, Cleland JGF, et al. Clinical practice update on heart failure 2019: pharmacotherapy, procedures, devices and patient management. An expert consensus meeting report of the Heart Failure Association of the European Society of Cardiology. Eur J Heart Fail 2019;21:1169-86. https://doi.org/10.1002/ejhf.1531.

[140] Wagner S, Merkling T, Metzger M, Bankir L, Laville M, Frimat L, et al. Water intake and progression of chronic kidney disease: the CKD-REIN cohort study. Nephrol Dial Transplant 2021. https://doi.org/10.1093/ndt/gfab036.

[141] Clark WF, Huang SH, Garg AX, Gallo K, House AA, Moist L, et al. The chronic kidney disease water intake trial: Protocol of a randomized controlled trial. Can J Kidney Heal Dis 2017. https://doi.org/10.1177/2054358117725106.

[142] Aliti GB, Rabelo ER, Clausell N, Rohde LE, Biolo A, Beck-da-Silva L. Aggressive Fluid and Sodium Restriction in Acute Decompensated Heart Failure. JAMA Intern Med 2013;173:1058. https://doi.org/10.1001/jamainternmed.2013.552.

[143] Rangaswami J, Bhalla V, De Boer IH, Staruschenko A, Sharp JA, Singh RR, et al. Cardiorenal protection with the newer antidiabetic agents in patients with diabetes and chronic kidney disease: A scientific statement from the American Heart Association. Circulation 2020. https://doi.org/10.1161/CIR.0000000000000920.

[144] Little RR, Rohlfing CL, Tennill AL, Hanson SE, Connolly S, Higgins T, et al. Measurement of Hba1C in patients with chronic renal failure. Clin Chim Acta 2013;418:73-6. https://doi.org/10.1016/j.cca.2012.12.022.

[145] Dungan KM, Han W, Miele A, Zeidan T, Weiland K. Determinants of the Accuracy of Continuous Glucose Monitoring in Non-Critically Ill Patients with Heart Failure or Severe Hyperglycemia. J Diabetes Sci Technol 2012;6:884-91. https://doi.org/10.1177/193229681200600420. 
[146] 6. Glycemic Targets: Standards of Medical Care in Diabetes-2021. Diabetes Care 2021;44:S73-84. https://doi.org/10.2337/dc21-S006.

[147] Beck RW, Bergenstal RM, Riddlesworth TD, Kollman C, Li Z, Brown AS, et al. Validation of Time in Range as an Outcome Measure for Diabetes Clinical Trials. Diabetes Care 2019;42:400-5. https://doi.org/10.2337/dc18-1444.

[148] Dungan K, Graessle K, Sagrilla C. The Effect of Congestive Heart Failure on Sensor Accuracy Among Hospitalized Patients with Type 2 Diabetes. Diabetes Technol Ther 2013;15:817-24. https://doi.org/10.1089/dia.2013.0094.

[149] Ponikowski P, Voors AA, Anker SD, Bueno H, Cleland JGF, Coats AJS, et al. 2016 ESC Guidelines for the diagnosis and treatment of acute and chronic heart failure: The Task Force for the diagnosis and treatment of acute and chronic heart failure of the European Society of Cardiology (ESC)Developed with the special contribution of. Eur Heart J 2016;37:2129-200. https://doi.org/10.1093/eurheartj/ehw128.

[150] Buse JB, Wexler DJ, Tsapas A, Rossing P, Mingrone G, Mathieu C, et al. 2019 update to: Management of hyperglycemia in type 2 diabetes, 2018. A consensus report by the American Diabetes Association (ADA) and the European Association for the Study of Diabetes (EASD). Diabetes Care 2020;43:487-93. https://doi.org/10.2337/dci19-0066. 